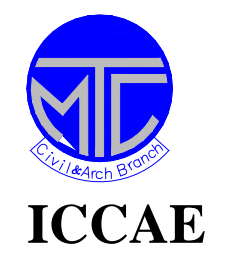

Military Technical College

Kobry Elkobbah,

Cairo, Egypt $7^{\text {th }}$ International Conference

Civil \& Architecture

Engineering

\title{
SHEAR STRENGTH OF CONCRETE EMBEDDED BEAMS AND HOLLOW BLOCK SLABS
}

\author{
AYMAN HUSSEIN HOSNY KHALIL ${ }^{1}$
}

\begin{abstract}
In Egypt, it is a common practice to utilize floor systems consisting of hollow block slabs resting on embedded beams having the same depth. For the embedded beams and the hollow block slabs, the current Egyptian Code requires that the shear resistance to be solely provided by concrete with no dependence on any form of shear reinforcement. Four international code requirements were reviewed and no similar provisions were found. In this paper, the shear strength of embedded beams and hollow block slabs with intermediate length (shear span-to-depth ratio of approximately 5 ) is evaluated. Nine medium-scale simply-supported conventionally reinforced concrete embedded beams and five full-scale hollow block one way slabs with normal concrete strength subjected to three-point monotonic loading were experimentally loaded to failure. The specimens were typically proportioned so that shear failure would preclude flexural failure. The study examines the shear strength of the tested specimens with special emphasize on the effect of shear reinforcement in the form of vertical stirrups with varying shapes, configuration, and amount. During testing, deflections, strains in main reinforcement, concrete, and stirrups were monitored. Recorded capacities of specimens with shear reinforcement reached as high as $300 \%$ of those without shear reinforcement. Laboratory recorded shear strengths at failure are compared with theoretical strengths calculated according to

1 Associate Professor, Structural Engineering Department, Ain Shams University, Cairo, Egypt, ayman hh khalil@yahoo.com, 1 Aly abdel Razik Street, Heliopolis, Cairo, Egypt, 11351, Phone +2 02 26238186, +2 012 2143230, Fax +2 0226238177 ,
\end{abstract}


the current Egyptian Code procedures and the reviewed international codes. Further, the shear capacity of tested specimens was assessed in the light of the modified compression field theory. Test results clearly demonstrated that the shear reinforcement significantly improved the shear capacity and enhanced the ductility of the tested specimens. As such, the study concludes that the vertical stirrups are effective as shear reinforcement in embedded beams and in one-way hollow block slabs. A simplified empirical formula for predicting the shear strength of such elements is also proposed based on the Egyptian Code provisions.

\section{KEYWORDS}

Shear strength; embedded beams; hollow block slabs; ribbed slabs; shear reinforcement; stirrups; modified compression field theory.

\section{INTRODUCTION}

Reinforced concrete hollow block slabs with embedded beams are commonly used in Egypt as floor systems. The system is well-known for being economic as it provides lower reinforcement ratios compared to flat slab systems. In addition, it gives less construction depths compared to traditional solid slabs and drop beams construction. Embedded beams and hollow block slabs may fail in flexure or in shear. The flexural capacity of these elements can be enhanced by increasing the area of steel reinforcement in both tensile and compressive sides. On the other hand, options for increasing the shear capacity of such elements are limited as the current Egyptian Code requires that the shear resistance of these elements to be solely provided by concrete with no dependence on any form of shear reinforcement. This requirement is very conservative and similar requirement was not found in any recognized international code. On the other hand, the code declares the enhanced capacity of these elements due to their typical large widths enabling sharing the load between week and strong areas and their limited depths (size effect). In this respect, the code assigns concrete of these element increased shear resistance (roughly $130 \%$ that of the concrete of regular beams). The code allows utilizing $50 \%$ of the enhanced capacity in the computation of the shear resistance of these elements.

In spite of the numerous research efforts directed towards estimating the shear capacity of concrete beams with limited depths and slabs, there is still a disagreement concerning the design principles that govern the shear design of concrete embedded beams and hollow block slabs and even regular beams. Current design methods for the general analysis and design of beams and slabs, include empirical design methods, design based on stress analysis and strut and tie modelling. There is a considerable discrepancy between these designs. As such, there is a need for experimental data on the behaviour of embedded beams and hollow block slabs. The objective of this research program is to investigate the shear behaviour of embedded beams and hollow block slabs. An experimental program was conducted to investigate the effect of the presence, amount, and shape of shear reinforcement in the form of vertical stirrups on the shear resistance of normal strength hollow block slabs and embedded reinforced concrete beams. Moreover, the effect of the embedded beam width to depth ratio is examined. Further, the experimental results presented in this paper are compared with the design models of 
several codes and methods. The purpose is to evaluate the different approaches and theories supporting these methods.

\section{RESEARCH SIGNIFICANCE}

ECCS 203 [1] requires that shear resistance of embedded beams and hollow block slabs to be provided by concrete only. No shear reinforcement is to be relied upon in computing the shear resistance. This paper examines the code requirements through an experimental investigation. The main objective of the experimental program was to examine the influence of providing shear reinforcement in the form of vertical stirrups on the general behaviour of embedded beams and hollow block slabs. Further, the influence of stirrup shape and anchorage details on the shear capacity of hollow block slabs is investigated. Therefore, the information in this paper has a direct relevance to structural engineering design practices.

\section{SHEAR OF EMBEDDED BEAMS AND SLABS IN INTERNATIONAL CODES}

\section{Egyptian Code ECCS 203}

The Egyptian Code (ECCS 203-2007) [1] computes the shear resistance of embedded beams and hollow block slab as,

$$
Q_{c u}=0.16 \sqrt{\frac{f_{c u}}{\gamma_{c}}} b_{w} d
$$

where $Q_{c u}$ is the concrete shear capacity, $f_{c u}$ is the concrete characteristic strength, $\gamma_{c}$ is concrete partial safety factor and equals $1.50, b_{w}$ is the width of the web, and $d$ is the effective depth of the section. The minimum web reinforcement ratio, $\rho_{w}$, in the form of vertical stirrups with a spacing limited to half the depth of the beam depends only on the type of steel and is computed as

$$
\rho_{w}=\frac{0.4}{f_{y}}
$$

where $f_{y}$ is the yield strength of the reinforcement. The code does not allow dependence on reinforcement to provide any shear resistance for embedded beams and slabs. On the other hand, the code computes the concrete shear resistance in regular beam as,

$$
Q_{c u}=0.24 \sqrt{\frac{f_{c u}}{\gamma_{c}}} b_{w} d
$$

Relying only on concrete to resist shear in regular beams is not permitted. As such minimum shear reinforcement as per Equation 2 is always required. Dependence on shear reinforcement is permitted with the shear resistance being computed as,

$$
Q_{u l t}=0.12 \sqrt{\frac{f_{c u}}{\gamma_{c}}} b_{w} d+\frac{A_{s t r} f_{y} d}{\gamma_{s} s}
$$

where $A_{s t r}$ is the area of vertical shear reinforcement, ${ }_{s}$ is steel partial safety factor and equals 1.15 , and $s$ is the stirrup spacing. 


\section{Eurocode 2 EN 1992}

The Eurocode 2 (EN 1992) [2] recommends formulas and values that are subject to national Annexes. For non-prestressed members with the minimum amount of shear reinforcement, the design value for the shear resistance $V_{R d, c}$ is given by:

$$
V_{R d, c}=\left[0.12 k\left(100 \rho_{l} f_{c k}\right)^{1 / 3}\right] b_{w} d
$$

with the following,

$$
\begin{aligned}
& k=1+\sqrt{\frac{200}{d}} \leq 2 \\
& \rho_{l}=\frac{A_{s l}}{b_{w} d} \leq 0.02
\end{aligned}
$$

where $f_{c k}$ is the concrete cylinder characteristic strength, $A_{s l}$ is the area of the longitudinal reinforcement, $b_{w}$ is the smallest width of the cross section in the tensile area. In Eurocode 2, the minimum web reinforcement, $\rho_{w, \min }$, depends on both the concrete and steel grades and is given as,

$$
\rho_{w, \min }=\frac{0.08 \sqrt{f_{c k}}}{f_{y k}}
$$

With $f_{y k}$ is the characteristic yield strength of steel. The code permits the minimum shear reinforcement to be omitted in members such as slabs (solid, ribbed or hollow core slabs) where transverse redistribution of loads being possible. The shear resistance of members with shear reinforcement is based on a truss model, whereby the value for the angle $\theta$ of the inclined struts in the web is limited as follows:

$$
1 \leq \cot \theta \leq 2.5
$$

For non-prestressed normal strength concrete members with vertical shear reinforcement, the shear resistance, $V_{R d}$, is the smaller of:

$$
\begin{aligned}
& V_{R d, s}=\frac{A_{s w}}{s} z f_{y w d} \cot \theta \\
& V_{R d, \text { max }}=\frac{0.6 f_{c d}}{\cot \theta+\tan \theta} b_{w} z
\end{aligned}
$$

With $A_{s w}$ is the area of shear reinforcement, $s$ is the spacing of stirrups, $f_{y w d}$ is the design yield strength of shear reinforcement, is the design compressive strength of concrete, $z$, the inner lever arm at the section of maximum bending moment and equals approximately 0.90 the effective depth of the member. The code allows depending on shear reinforcement in all types of elements including slabs and embedded beams.

\section{British Standard BS 8110}

The British Code BS 8110 [3] computes the concrete shear capacity, $V_{c}$, in beams and slabs with shear span to depth ratio greater than 2 as follows.

$$
V_{c}=\frac{0.79}{\gamma_{m}}\left(\frac{100 A_{s}}{b_{v} d}\right)^{1 / 3}\left(\frac{400}{d}\right)^{1 / 4}\left(\frac{f_{c u}}{25}\right)^{1 / 3} b_{w} d
$$


where $f_{c u}$ is the concrete characteristic strength in $\mathrm{MPa}, \gamma_{m}$ is a partial safety factor for concrete and equals $1.25, A_{s}$ is the area of the tension reinforcement, $b_{v}$ is the beam width, and $d$ is the depth. BS 8110 ignores the effect of concrete compressive strengths higher than $40 \mathrm{MPa}$ for evaluating the concrete contribution in shear resistance. Additionally, the effects of reinforcement ratio and beam depths are restricted to less than 0.03 and greater than $400 \mathrm{~mm}$, respectively. The minimum web reinforcement ratio, $\rho_{w}$, is

$$
\rho_{w}=\frac{0.4}{0.95 f_{y}}
$$

where $f_{y}$ is the yield stress of reinforcement in MPa. It should be noted that BS 8110 permits omitting the shear reinforcement completely for low importance beams in which shear stresses are less than half the concrete shear strength. The code allows the use of shear reinforcement for all types of concrete elements. In such case, the shear capacity, $V$, is computed as:

$$
V=V_{c}+\frac{0.95 A_{s v} f_{y} d}{s_{v}}
$$

With $A_{s v}$ is the area of shear reinforcement, $s_{v}$ is the spacing of stirrups, and $f_{y}$ is the design yield strength of shear reinforcement. The code does not prevent dependence on shear reinforcement in all types of elements including slabs and embedded beams.

\section{American Concrete Institute ( $\mathrm{ACl} 318)$}

$\mathrm{ACl} 318$ [4] sets the concrete contribution equal to the shear at inclined cracking because beams without shear reinforcement often failed simultaneously with inclined cracking. The concrete contribution term, $v_{c}$, for non-prestressed members has remained unchanged for almost 30 years. The nominal shear capacity, $V_{n}$, of nonprestressed members is the sum of the concrete contribution, $V_{c}$, and shear reinforcement contribution, $V_{s}$. The concrete contribution term, $V_{c}$, can be calculated for concretes with compressive strength up to $70 \mathrm{MPa}$ by either of the following two equations.

$$
\begin{aligned}
& V_{c}=\left(0.16 \sqrt{f_{c}^{\prime}}+17 \rho_{w} \frac{V_{u} d}{M_{u}}\right) b_{w} d \leq 0.29 \sqrt{f_{c}^{\prime}} b_{w} d \\
& V_{c}=0.17 \quad f_{c}^{\prime} b_{w} d
\end{aligned}
$$

In these equations, $f_{c}^{\prime}$ is the concrete cylinder compressive strength, $\mathrm{d}$ is the depth of the member, $\rho_{w}$ is the tensile reinforcement ratio, $V_{u}$ is the ultimate shear force at the section, and $M_{u}$ is the corresponding ultimate moment at the same cross section. It should be noted that Equation (15) is seldom used by practicing engineers because of its added complexity and the fact that for most current beam and slab design it provides little increase in shear strength over that provided by Equation (16). As with BS 8110, ACl-318 permits omitting the web reinforcement in beams with shear stresses below half the concrete shear strength. For beams with height not greater 
than the largest of $250 \mathrm{~mm}, 2.5$ times thickness of flange, or 0.5 the width of web, slabs, and footings, the code omits the shear reinforcement if the concrete shear capacity is higher than the shear demand because there is a possibility of load sharing between weak and strong areas. Otherwise, the minimum web reinforcement, set as a function in both the concrete and steel grades as in Equation 17 , shall be used.

$$
\rho_{w}=\frac{0.062 \sqrt{f_{c}^{\prime}}}{f_{y}}
$$

With $f_{y}$ is the design yield strength of shear reinforcement. $\mathrm{ACl} 318$ allows the use of shear reinforcement for all types of concrete elements. In such case, the shear capacity, $V_{n}$, is computed as:

$$
V_{n}=V_{c}+\frac{A_{v} f_{y} d}{s}
$$

With $A_{v}$ is the area of shear reinforcement, $s$ is the spacing of stirrups. The code allows dependence on shear reinforcement in all types of elements including slabs and embedded beams.

\section{The Canadian Standard CSA A23.3-04}

The Canadian Standard CSA A23.3-04 [5] provides two approaches for predicting the shear strength of reinforced concrete members: (1) the simplified method, and (2) the general method. The simplified method is similar to the of $\mathrm{ACl} 318$ method except that the effect of member size is considered. The general method is based on the Modified Compression Field Theory (MCFT) [6]. The shear resistance, $V$, of non-prestressed members is divided into the concrete contribution, $V_{c}$, and shear reinforcement contribution, $V_{s}$. The concrete contribution term, $V_{c}$, can be taken by:

$$
\begin{aligned}
V_{c} & =0.20 \sqrt{f_{c}^{\prime}} b_{w} d \text { when } \rho_{v} \geq 0.06 \sqrt{f_{c}^{\prime}} / f_{y} \text { or } d \leq 300 \mathrm{~mm} \\
\text { Or } \quad V_{c} & =\frac{260}{1000+d} \sqrt{f_{c}^{\prime}} b_{w} d \geq 0.10 \sqrt{f_{c}^{\prime}} b_{w} d \text { when } \rho_{v} \leq 0.06 \sqrt{f_{c}^{\prime}} / f_{y} \text { or } d>300 \mathrm{~mm}
\end{aligned}
$$

With $\rho_{v}$ equals the shear reinforcement ratio. The steel contribution is the same as per $\mathrm{ACl}$ 318. The code permits using shear reinforcement in slabs and shallow or embedded beams.

For comparison purposes, an embedded beam having $200 \mathrm{~mm}$ depth, a reinforcement ratio of $1 \%$ and the minimum shear reinforcement was found to have ultimate shear strength of $0.80,0.70,0.99,0.75$, and $0.89 \mathrm{~N} / \mathrm{mm}^{2}$ according to ECCS 203-07, Eurocode EN 1992-1, BS 8110, ACI 318 and CSA A23.3, respectively. From the above, it is clear that different predictions for the shear strength of concrete elements are provided in different codes. Only, the Egyptian Code neglects the enhancement in the shear capacity due to using shear reinforcement in embedded beams and hollow block slabs. To compute shear strength of concrete regular and embedded beams and slabs having web reinforcement, simple superposition of stirrups and reinforcement contributions to shear capacity is recommended by BS 8110, ACI 318, and CSA 23.4. The Egyptian Code ECCS 203, however, computes 
the shear strength as the sum of half the concrete shear resistance and the stirrup forces.

\section{MODIFIED COMPRESSION FIELD THEORY}

Collins and Mitchell [6] propose a more rational method or approach to the shear design "problem". The approach is based on fundamental principles rather than on empirical equations. It treats the stress-strain characteristics of the cracked concrete using average stresses and strains in the concrete and utilizes equilibrium and compatibility of strains. The crack pattern is also idealized as a series of parallel cracks occurring at a constant angle to the longitudinal direction. The theory considers that the shear strength of concrete at a crack location is dependent on the width of the crack as well as the maximum aggregate size used. This method accounts for the strain softening of the diagonally cracked concrete in compression and also accounts for the tensile stresses in the cracked concrete. The method has given accurate predictions of the shear response in beam elements [7]. Details of the method can be found in numerous references $[6,7,8]$.

The Windows-based computer program "RESPONSE 2000" has been developed at the University of Toronto by Collins and Bentz [9]. This program uses a "planesection" analysis technique and uses the MCFT for shear. The technique assumes that plane sections remain plane, combined with a dual-section analysis and the MCFT to determine the shear response. It performs sectional analyses using the stress-strain relationships for the diagonally cracked concrete and the complete stress-strain relationship for the steel reinforcement. The analysis accounts for the sectional properties and the combined loading conditions (moment, shear and axial load), and provides the response of a section up to and beyond failure. The program provides full graphical output of stresses and strains at key stages of loading. A version of this program will be used in the current investigation to predict the response of the specimens tested according to the MCFT.

\section{EXPERIMENTAL PROGRAM}

The experimental investigation consisted of designing, casting, and testing fourteen reinforced concrete slab and beam specimens. The test program was conducted in the Reinforced Concrete Laboratory of Ain Shams University. The concrete compressive strength at the age of tests ranged from 25 to $27 \mathrm{MPa}$. The primary design variables were the shear reinforcement (vertical stirrups) presence, shape, and density. This section describes the objective of the experimental program, the details of the test specimens, material properties, the utilized instrumentation, and the testing procedure. The main objectives of the experimental program were to: (1) study the shear strength of embedded beams and hollow block slabs without shear reinforcement, (2) examine the effect of shear reinforcement presence, shape, and density on the behaviour of embedded beams and hollow block slabs, and (3) propose recommendations for the Egyptian Code equations that predict the shear capacity of embedded beams and hollow block slabs.

\section{Test Specimens}


In order to achieve the previous objectives, fourteen slab and beam specimens were designed and tested under monotonically increasing vertical loads. The geometry and reinforcement details of the specimens are shown in Figure 1 and in Table 1. The specimens were designed utilizing the MCFT such that shear failure would preclude flexural failure [6]. The shear span-to-depth ratio, a/d, of all specimens was less than or equal five, in order to produce a shear critical specimen [10]. The longitudinal steel was evenly distributed along the width of the specimens leaving a $10 \mathrm{~mm}$ clear cover on each side and the bottom. Except for Specimens S5, B5, and $\mathrm{B} 6$, specimens had one layer of bottom steel.

The test specimens were categorized into three groups. The first group, slab specimens, was composed of five hollow block slabs. As shown in Figure 1, slab cross section consists of two ribs with a hollow block in-between. The specimen height and width were $200 \mathrm{~mm}$ and $600 \mathrm{~mm}$, respectively. The topping slab thickness is $80 \mathrm{~mm}$ thick with the block height being $120 \mathrm{~mm}$. The rib width is 100 $\mathrm{mm}$ and the block width is $400 \mathrm{~mm}$. The slab overall length was $1900 \mathrm{~mm}$ with a clear span of $1700 \mathrm{~mm}$ between the two simple supports. As such, the shear span to depth ratio was 4.75. Eight blocks were used leaving a solid part of $50 \mathrm{~mm}$ next to the support section. The specimens vary in the longitudinal reinforcement and in the presence, amount and shape of stirrups. Tensile reinforcement ratios ranged from $1.8 \%$ to $8.8 \%$ with the compressive reinforcement ratios varying between $0.3 \%$ and $4.4 \%$. It should be noted that the longitudinal steel ratios were higher in some specimens than that allowed by ECCS 203 [1]. However, these ratios were required to prevent flexural failure. The shear reinforcement (vertical stirrups) ratios ranged from $0 \%$ to $1 \%$. Where shear reinforcement was provided, its ratio was higher than the minimum required by ECCS 203 [1]. In S1, no stirrups were provided along the span. Vertical stirrups were used at both ends only to hold steel top and bottom bars in positions. In S2, S3 and S4, the same percentage of shear reinforcement was provided $\left(\rho_{w}=0.50 \%\right)$. S2 has open legged stirups satisfying the requirements of ECCS 203 for hollow block slabs (see Table 1 and Figure 2) with respect to shape and spacing. S3 has the same shear reinforcement; however, detailed as per ECCS 203 requirements for beams (closed stirrups with standard hooks). S4 has the same ratio of vertical stirrups, however, the spacing was reduced to $100 \mathrm{~mm}$ and one legged stirrup (hoop) was used for each rib. In S5, the percentage of shear reinforcement $\rho_{w}$ was $1 \%$ requiring high percentage of tensile reinforcement along with considerable compression reinforcement. All stirrups were normal mild 8-mm diameter reinforcement denoted as R8 in Table 1.

In Group II, a total of six beams were tested with all beams sharing the same concrete dimensions. Overall length, clear span, and height were 1800,1600, and $220 \mathrm{~mm}$, respectively. In order to avoid flexural compression failure and to simulate the behaviour of embedded beams, specimens were equipped with compression flanges having thickness and width of $80 \mathrm{~mm}$ are $600 \mathrm{~mm}$, respectively. Web width is $200 \mathrm{~mm}$. The beam total depth was $220 \mathrm{~mm}$. The beam effective depth to web width ratio was 0.95 , which meets the criteria of ECCS-203 for embedded beams. In Specimens, B1 and B2, no stirrups were used along the span of the beams. Two stirrups, one at each end, were used to hold top and bottom reinforcement in position. B2 has higher reinforcement than B1 to examine the effect of longitudinal reinforcement on the shear capacity of embedded beams. In B3 and B4, 8-mm 2-leg 
mild steel stirrups were spaced at $200 \mathrm{~mm}$ and $100 \mathrm{~mm}$, respectively resulting in shear reinforcement ratios, $\rho_{w}$, of $0.25 \%$ and $0.5 \%$. In B5 and B6, 10-mm 2-leg stirrups were spaced at $100 \mathrm{~mm}$ and $50 \mathrm{~mm}$, respectively to give $\rho_{w}$ of $0.78 \%$ and $1.57 \%$. The $10-\mathrm{mm}$ stirups were high grade deformed steel bars. It should be noted that stirrup spacing in B3 violated the maximum spacing limit set by ECCS 203.

In Group III, a total of three embedded beams were tested with the same concrete dimensions. Overall length, clear span, and height were 1900, 1700, and $200 \mathrm{~mm}$, respectively. Flange thickness and width are $80 \mathrm{~mm}$ are $600 \mathrm{~mm}$, respectively. Web widths were double those in Group II specimens, i.e., $400 \mathrm{~mm}$. Depth to web width ratio was approximately 0.43 . Reinforcement ratios ranged from $1.8 \%$ to $4.5 \%$ approximately. In Specimen R, no stirrups were used. In W1 and W2, 8-mm 4-leg mild steel stirrups were spaced at $200 \mathrm{~mm}$ and $85 \mathrm{~mm}$, respectively. This corresponds to shear reinforcement ratios of $0.25 \%$ and $0.6 \%$. Stirrup spacing in W1 violated the maximum spacing requirements by ECCS 203.

\section{Materials and Casting}

Concrete mix with proportions per cubic meter by weight is as follows: $340 \mathrm{~kg}$ cement, $1250 \mathrm{~kg}$ crushed limestone, $640 \mathrm{~kg}$ sand, and 160 litres of water. Concrete strengths were determined from standard cube samples (150 mm side length) samples taken from the concrete batch for each specimen. Concrete compressive strengths were 25,25 , and $27 \mathrm{MPa}$ for Group I, II, and III, respectively. The longitudinal tensile reinforcement in all specimens and the 10-mm diameter stirrups were of nominal proof strength $400 \mathrm{MPa}$ deformed bars (denoted by $\mathrm{T}$ ). On the other hand, the 8-mm diameter mild steel stirrups (denoted by R) were of nominal yield stress of $240 \mathrm{MPa}$. The reinforcing bars were cut to the desired lengths and were bent according to the Egyptian Code. In addition, the tensile reinforcement was extended and bent beyond the support sections to ensure sufficient anchorage capacities. Reinforcement cages were placed on rigid floor in wooden forms (see Figure 2 and Figure 3). Specimens were cast utilizing ready mixed concrete as shown in Figure 4. Concrete was compacted in the forms using a hand-held vibrator. Sides of forms were stripped two days after casting and specimens were water cured for ten days.

\section{Test Procedure and Instrumentation}

All specimens were tested at the Reinforced Concrete Laboratory of the Department of Structural Engineering of Ain Shams University, in three points bending, as shown in Figure 5. The specimens were supported on a pair of rollers and steel beam and a bearing plate at each support. The point load was applied at the mid point between supports. The load transfer from the loading frame to the specimens was through bearing plates and steel rigid beams. For Group I Specimens, the vertical load of the test machine was equally distributed between the two ribs of the hollow block slab. The loading was applied using a manually operated hydraulic jack with a capacity of $600 \mathrm{kN}$ and an accuracy of $10 \mathrm{kN}$. Vertical load was applied at an increment of 10 $\mathrm{kN}$. Each load increment was applied during a period of about two minutes at the end of which the load was held constant for a period of about four minutes, to allow for measurements and observations. Loading continued up to failure of the test 
specimen. During testing, the general deformational behaviour was tracked. The development of cracks was marked along the sides of the test specimens. In addition, specimen deflections, the concrete strains, longitudinal reinforcement strains, and the stirrup strains were measured. Mid span deflections were measured using Linear Variable Distance Transducers (LVDT) of accuracy $0.01 \mathrm{~mm}$. The transducers were attached to independent wooden frames resting on the floor of the test bed. The tensile strains in the longitudinal tensile reinforcement at the mid-span section of the tested beams as well as the tensile strains in 2 or 3 vertical stirrups mid way between the point load and the support (around quarter span location) were measured using electrical wire strain gauges of $10 \mathrm{~mm}$ length and $120 \mathrm{Ohm}$ resistance. These gauges were glued to the reinforcement and were covered by waxing material to protect them during handling and casting.

\section{TEST RESULTS}

In this section, the observed behaviour of the 14 slab and beam specimens is presented. Among the experimental results recorded were deflections, longitudinal steel strains, concrete strains, stirrup strains and crack development and propagation at different load stages. Flexural cracking, shear cracking, and failure loads for each specimen are given in Table 1 and in Figure 6 . Figure 7 and Figure 8 present photographs of the specimens taken after their failure. Figure 9 shows the relation between the shear reinforcement ratio and the ultimate shear strength of the tested specimens. Figure 10 through Figure 12 show the relation between the mid span deflection and the applied loads for Groups I, II, and III, respectively. Figure 13 through Figure 15 show the relation between the main flexural strains and the applied loads. Figure 16, Figure 17, and Figure 18 show the relation between the stirrup strains and the applied loads.

\section{General Behaviour and Failure Modes}

The general behaviour of all the tested specimens was relatively similar. In this respect, the crack development in all tested beams followed a similar pattern. First, nearly vertical flexural cracks initiated at approximately the mid span sections of the tested specimens. With further loading, new flexural cracks formed in the shear spans and curved toward the loading points. As shown in Table 1, flexural cracking loads differed from one specimen to another. Within the same group, specimens with lower longitudinal reinforcement had lower cracking loads. Additionally, differences were noticed in the cracking load from one group to another. Differences in cracking loads among different groups are attributed to the differences in the concrete cross section and the concrete strength leading to changes in both section modulus and the tensile strength. After the first crack formation, additional nearly vertical cracks appeared near the mid span sections. At intermediate loading stages, inclined flexural cracks initiated in the shear span and propagated with increased inclination towards the supports. Unlike the flexural cracks which formed at the bottom and gradually developed towards the compression flange, the diagonal cracks formed through a substantial depth of the section. After its formation, its lower end extended forming splitting crack in the concrete along the longitudinal reinforcement and widened existing flexural cracks. On its upper end, the crack developed and propagated towards the top flange. After reaching the flange, the 
inclined cracks continued propagation horizontally just under the flanges towards the point of load application. Except for Specimens S5 and B6, the crack extended into the compression flange causing the specimen to fail in shear diagonal tension. Specimens S5 and B6 failed due to extensive cracking of the web and crushing of concrete between cracks in the web near the support causing combined shear compression and bearing failure.

Specimens without shear reinforcement (S1, B1, B2, and R) had few shear cracks with the failure cracks being inclined at slopes of approximately $20^{\circ}$. This is in line with BS-8110 [3] prediction that beams with no shear reinforcement fail with crack inclinations of less than $30^{\circ}$. These specimens crack patterns, as shown in Figure 7 and Figure 8 , were characterized by a majority of vertical flexural cracks in the midspan region together with some inclined ones towards the supports. It is worth mentioning that the failure of these specimens occurred in a brittle manner and abruptly. The ultimate shear capacity was higher than the first load at which the diagonal cracking causing failure developed by the following percentages: $7 \%$ for $\mathrm{S} 1$, $29 \%$ for B1, $50 \%$ for B2, and $50 \%$ for R. It should be noted that ratios for beam specimens (B1, B2, and R) are higher than that of S1 and the typically recorded ratios in previous investigations [11]. This is probably because of the enhancement of the shear capacity due to compression flange presence. The flange presence on both sides of the web required extra force for the crack to develop into the compression region.

On the other hand, specimens containing stirrups presented a more ductile response. After the formation of the first shear crack, stirrups started to contribute and further shear cracks developed and widened. At failure, the shear crack propagated into the top compression flange towards the point of load application. Failure cracks were inclined at slopes varying between $30^{\circ}$ and $45^{\circ}$. The crack patterns were characterized by vertical flexural cracks in the mid-span region together with some inclined ones towards the supports with larger number of cracks compared to specimens without stirrups. Apparently, increasing the stirrups ratio boosted the ratio of failure loads to shear cracking loads. In Group I specimens, the ratios of the ultimate loads to shear cracking loads were $128 \%, 138 \%, 140 \%$, and $152 \%$ for $\mathrm{S} 2$, S3, S4, and S5, respectively. S2, S3, and S4 had shear reinforcement ratio of $0.50 \%$, while S5 had a shear reinforcement ratio of $1 \%$. Similar trends were observed in Groups II and III. These trends can be attributed to the increase in the tensile resistance of the section due to the composite action of stirrups and concrete.

In Group I, Slabs S1, S2, S3, S4, and S5 failed in shear at loads of 140, 180, 220, 210 , and $260 \mathrm{kN}$, respectively. All slabs had the same concrete dimensions. As such, the increase in the slab shear capacity is clearly attributed to the increases in the shear reinforcement ratio. The beneficial nature of failure was noticed as the shear reinforcement ratio increased. This is evident through the larger number and more uniform distribution of cracks going from S1 to S5. The higher margins between the shear cracking and the failure loads going from $S 1$ to $S 5$, provide further evidence of the more favourable failures. Slabs S2, S3, and S4 had the same shear reinforcement ratio; however, they differed in the shape of stirrups (as in Figure 2 and Table 1). The shape of stirrups in $S 2$ and $S 3$ follows the detailing requirements of ECCS 203 for hollow block slabs and regular beams, respectively. Spacing of 
stirrups in these specimens is $200 \mathrm{~mm}$ (larger than the depth of the specimen) following the requirements of ECCS 203 for slabs; however, violating the requirements of ECCS 203 for beams. In S4, open legged stirrups (hoops) with a spacing of $100 \mathrm{~mm}$ (approximately 0.59 the specimen depth) were used. Among these specimens, S3 had the highest shear cracking and failure loads. This clearly indicates that the shape of stirrups in S3 is the best among the three shapes. As such, it should be recommended to use well-anchored stirrups in both tension and compression sides as shear reinforcement. On the other hand, the failure load of S4 was higher than that of S2 indicating that utilizing single legged stirrup at a spacing of $100 \mathrm{~mm}$ is more efficient than using open stirrups at a spacing of $200 \mathrm{~mm}$. It is worth mentioning here that it was noted that the $90^{\circ}$ bent of the open legged stirrup around the main longitudinal reinforcement in S4 started opening slightly before failure causing concrete cover spalling as shown in Figure 7.

In Group II, Beams B1, B2, B3, B4, B5, and B6 failed in shear at loads of 155, 180, $200,280,340$, and $400 \mathrm{kN}$, respectively. As for Group I, all the beam specimens shared the same concrete dimensions. As such, the increase in the beam shear capacity is clearly attributed to the presence and increases in the stirrup ratios. Beam specimens with stirrups had larger number of uniformly distributed cracks leading to more ductile nature of failure. The ratios between the shear failure and shear cracking loads were $153 \%, 200 \%, 212 \%$, and $200 \%$ for B3, B4, B5, and B6. The higher margins between the shear cracking and the failure loads from B3 to B6, provide further evidence of the more favourable failures. Both Beams B1 and B2 had no shear reinforcement; however, B2 had higher main reinforcement (see Table 1). The failure load of B2 is higher than that of B1 indicating the beneficial effect of the dowel action on the shear capacity.

In Group III, Beams R, W1, and W2 failed in shear at loads of 255, 380, and $550 \mathrm{kN}$, respectively. As for the previous groups, the increase in the beam shear capacity is attributed to the presence and increases in the stirrup ratios. Beam specimens with stirrups had larger number of uniformly distributed cracks leading to more ductile nature of failure. The ratios of shear ultimate loads to shear cracking loads were $180 \%$ and $196 \%$ for $\mathrm{W} 1$, and $\mathrm{W} 2$, respectively. The higher margins between the shear cracking and the failure loads going from W1 to W2 provide proof of the more favourable failures and the contribution of stirrups in resisting shear in embedded beams.

Figure 9 shows the relation between the normalized shear reinforcement (stirrup) ratio and the ultimate shear strength of the tested specimens. The shear strength, $q_{u l t}$, is computed as per ECCS 203 requirements (Equation 4-13)

$$
q_{u l t}=\frac{Q_{u}}{b_{w} d}
$$

In which, $Q_{u}$ is failure shear force, $b_{w}$ is the web width, and $d$ is the effective depth. The normalized stirrup reinforcement ratio, $\rho_{s h}$, is computed as

$$
\rho_{s h}=\frac{n A_{s}}{b_{w} S} \frac{f_{y}}{240} \sqrt{\frac{f_{c}}{25}}
$$


In which $n A_{s}$ is the area of shear reinforcement, $S$ is the spacing of stirrups, and $f_{y}$ is the yield strength of stirrups. To consider the influence of different yield or proof strengths of stirrups, the term $\frac{f_{y}}{240}$ is suggested to be added to the previous equation. Additionally to normalize the effect of concrete strength, the term $\sqrt{\frac{f_{c}}{25}}$ has also been added. For concrete, normalization was performed in relation to the square root of the concrete strength in line with ACl 318-08 and ECCS 203-07. Three additional plots are present in this figure. In the first, the relation between the shear strength as predicted by ECCS 203 for hollow block slabs and embedded beams and the stirrups ratio denoted by (qc slabs ECCS 203) is plotted. The plot is a straight line with no slope entailing that the shear reinforcement has no impact on the shear strength of concrete elements. The second plot shows the relation between the shear strength of the regular beams as predicted by ECCS 203 and the stirrups ratio denoted by (qc+qs ECCS 203). Two limits are imposed on this plot: one for the maximum shear strength and the other for the beams without the minimum shear reinforcement. The third plot provides the shear strength of a group of regular beams tested by the author in a previous investigation [11].

The figure emphasizes the role of stirrups in enhancing the shear capacity of embedded beams and hollow block slabs. Recorded shear strengths ranged from $1.80 \mathrm{~N} / \mathrm{mm}^{2}$ to $5.26 \mathrm{~N} / \mathrm{mm}^{2}$. Clearly, the figure shows that all test specimens had shear strengths higher than that predicted by ECCS 203 for regular beams or for embedded beams and hollow block slabs. The figure undoubtedly shows that as the shear reinforcement ratio increased, the ultimate shear strength increased. The enhancement was better in Groups II and III (beam specimens) than in Group I (slab specimens) as evidenced by the steeper slopes of the curves for Groups II and III. No apparent reason was thought to explain the difference in enhancements between Group I from one side and Groups II and II on the other side. One significant discrepancy, which might have contributed to the difference, is that specimens in Group I had L-shaped construction (with top slab projecting from one side of the web only) and those of Groups II and III are T-shaped. Alternatively, the figure shows that the enhancement in the shear capacity is reduced for stirrups ratios greater than roughly $1 \%$ (flatter slope of the relation). The shear strength of specimens in Group II and Group III having the same ratio of web reinforcement are approximately equal. This indicates that, for beams satisfying the condition of embedded beams, the depth-width ratio has insignificant effect on the shear resistance. It is clear from the figure that the shear strength of embedded beams and hollow block slabs is consistently higher than those of regular beams. This justifies the Egyptian Code assigning the embedded beams and hollow block slabs higher shear resistance than regular beams.

\section{Mid Span Deflection}

Figure 10 to Figure 12 show the load- mid span deflection relationships for the tested specimens. Inspecting the responses of the tested specimens substantiates the results presented in the previous section with respect to the general behaviour and ductility. Inspecting the load-deflection behaviour revealed that specimens with 
higher reinforcement ratios had stiffer responses to loading in all loading stages. This was typically noted in the three tested groups. Expectedly, the deflection increased almost linearly with loading in the pre-cracking stage. In this stage, the strains in steel and concrete are relatively small and both materials are in the elastic portion of their respective responses. In the post-cracking stage, there are slight changes of slope in the load deflection curves due to cracking. Cracking moved the neutral axis towards the compression flanges, and thus, increased the curvature and deflections. After cracking, deflections increased approximately linearly with load. Again, each specimen exhibited different post-cracking load deflection response depending upon its reinforcement ratio. Comparing any two specimens within the same group revealed that the specimen with higher main steel ratio experienced less deformation at the same load level. On the other hand, inspecting the behaviour showed that shear reinforcement had no significant impact on deflection at a given load level. For example, S2, S3, and S4 with the same shear reinforcement ratio experienced slightly different deflections in different loading stages. On the other hand, Specimens B3 and B4 (same longitudinal reinforcement ratio however different shear reinforcement ratios) had approximately equal deflections in different loading stages. Load deflection curves for specimens heavily reinforced for shear (S5, B5, and B6) experienced some change in slopes at roughly $90 \%$ of the ultimate loads, causing considerable increases in the deflection at failure. The change in slope is attributed to the tensile reinforcement approaching the yield strength as a result of the enhanced shear capacity provided by the shear reinforcement.

To examine the ductility of the tested specimens, recorded deflections in the stage just preceding failure (at a load $10 \mathrm{kN}$ less than the ultimate load) were compared. In Group I, deflections were 8.84, 9.34, 12.3, 10.2, and $9.20 \mathrm{~mm}$, for S1 through S5, respectively. In Group II, deflections were 6.80, 6.60, 8.50, 16.10, 17.50, and 18.90 $\mathrm{mm}$, for B1 through B6, respectively. In Group III, deflections were 6.76, 11.00, and 11.30 for $\mathrm{W}, \mathrm{R} 1$, and $\mathrm{R} 2$, respectively. Increased deflections were noticed when moving from a specimen with lower shear reinforcement to the next with higher shear reinforcement within each group. Exception was noted in Group I when moving from S3 to S4 and from S4 to S5, this is probably because of the large increase in the flexural reinforcement which enhanced the flexural stiffness of these specimens considerably. Nevertheless, it can be judged that introducing the shear reinforcement enhanced the ductility of the tested specimens and that raising the shear reinforcement reduced the fragility of these specimens resulting in less brittle behaviour at failure.

\section{Reinforcement Strains}

Figure 13 through Figure 15 show the applied load-tensile strain relationships in the flexural bottom steel bars at the mid-span section of the tested specimens. A common observation from the figures is that all specimens failed before their tensile reinforcement reaches its proof limit, indicating the shear nature of failure in all test specimens. In the pre-cracking stage, the strains were relatively small. A comparison of load strain plots for all tested specimens shows that specimens with higher reinforcement ratios have lower steel strains in the pre-cracking stage due to a higher section modulus. After cracking, there is a change of slope in the load tensile strain curves. Cracking reduced the neutral axis depth, and thus, increased strains in 
the tension reinforcement. Steel strains increased approximately linearly with load in the post-cracking stage with different load-strain responses up to the failure load. Specimens with web reinforcement did not behave differently from those without any shear reinforcement. In this respect, the maximum recorded strain in specimens without shear reinforcement was $0.19 \%$ and that in specimens with web reinforcement was $0.22 \%$.

Comparing the responses of specimens within the same group revealed that specimens with higher reinforcement ratios had lower strains at the same load level compared to specimens with lower reinforcement ratios. The tensile reinforcement strains of slab specimens S1 through S5, Beams B1 through B6, and wide beam specimens $\mathrm{R}, \mathrm{W} 1$, and $\mathrm{W} 2$ confirm this finding. Another finding previously extracted from the deflection responses of Figure 11, is again confirmed when comparing the flexural tensile steel strain responses of Beams B2 (without shear reinforcement) and B3 (with shear reinforcement) of Figure 14. In fact, approximately similar strains where recorded in these beams implying that shear reinforcement had insignificant effect on the flexural response of the specimens.

\section{Stirrup Strains}

Figure 16 through Figure 18 plot the load-maximum tensile strain relationships in the vertical legs of stirrups around quarter span section of the tested specimens. At least, two stirrups were instrumented per specimen. Highest recorded strains are plotted in the figures. During early loading stages (before shear cracking), the strains were compressive with small values (less than 100 micro-strain). This is a common observation among the three figures. Compressive strains resulted from the fact that the load was applied on the top surface of the test specimens. After shear cracking, the stirrups develop tensile strains. This provides a clear indication that the stirrups were successful in resisting shear stresses in the slab and beams specimens of the current study. For the Slab Specimens S2 to S4, the rate of strain increase was small just after cracking and increased quickly as the specimens approached the ultimate load. Similar observation was recorded for Groups II and III specimens, in which the rate of strain increase was substantial from cracking stage and up to failure. Figure 16 shows that stirrups of S2, S3, and S4 reached $70 \%, 100 \%$, and $60 \%$ of the yield strains, respectively. All the three specimens had the same shear reinforcement ratio, however, with different stirrup detailing (see Figure 2). The figure gives a further indication that $\mathrm{S} 3$ had the best detailing as stirrups in this specimen were capable of reaching the yield. Although $\$ 4$ had higher failure load than S2, the recorded stirrup strains in S4 were lower than those in S2. A possible explanation is the closer spacing of stirrups in $\mathrm{S} 4$ controlled the concrete shear crack width driving the concrete contribution to shear resistance to be higher. In Specimen S5 which failed by diagonal compression, the maximum recorded strains were $70 \%$ of the yield strain. This gives a further indication on the compressive nature of failure. Overall, it can be judged that the contribution of stirrups resulted in the less brittle behaviour at failure as evidenced by the previously presented deflection plots. In Group II, the maximum recorded stirrup strains as percentage of the yield or proof strains were $120 \%, 150 \%, 100 \%$, and $65 \%$ that occurred in B3, B4, B5, and B6, respectively. In Specimens B3 and B4, the stirrups reached and exceeded the yield strain causing the diagonal cracks to widen considerably and extended horizontally 
just below the compression flange. This invited the neighbouring stirrups to contribute in resisting shear before the crack finally diagonally extending into the compression flange causing the specimen to fail. Similar observations were noted for B5 in which the stirups were of high grade steel reaching the proof strain at failure. In B6, however, the stirrups did not reach the proof strain at failure as the specimen had a diagonal compression failure. Group III had two specimens with stirrups. Stirrups in both these specimens reached the yield at failure. Once more, this ensures that the stirrups were effective and contributed to the resistance of shear in embedded beams.

\section{PREDICTION OF SHEAR BEHAVIOUR USING MCFT}

The computer program Response 2000 was used to obtain predictions according to MCFT. It is important to realize that for the shear span-to-depth ratios in the experimental program, $\mathrm{a} / \mathrm{d}=4.5$ to 5 , sectional analysis is appropriate [12]. For the predictions of the test results in this research program, the location chosen for the sectional analysis was taken at a distance equal to the effective depth, d, from the edge of the loading plates. This section is just outside of the disturbed region around the loading point and is the most critical section for combined shear and moment effects. The measured material properties were used for the predictions as well as the actual cross sectional dimensions. The program outputs the ultimate loads, the load deflection graphs, and the crack propagation diagrams. For Group I, the ultimate loads obtained from Response 2000 are 57, 151, 151, 179, and $254 \mathrm{kN}$, for S1, S2, S3, S4, and S5, respectively. For Group II, the ultimate loads were 68, 85, $140,207,320$, and $390 \mathrm{kN}$ for B1, B2, B3, B4, B5, and B6, respectively. For Group III, the ultimate loads were 118,240 , and $400 \mathrm{kN}$, for $\mathrm{R}, \mathrm{W} 1$, and $\mathrm{W} 2$, respectively. Figure 19 compares experimental shear strength with the shear strength predictions applying ECCS 203-07 model for regular beam and using RESPONSE 2000. The crack propagation diagrams for Group II Specimens are shown in Figure 20. The figure gives the crack inclinations and widths at failure for the six beam specimens. The figure shows that the maximum crack widths are those of the inclined shear cracks mid way between the support and the point loads. This reflects that failure being caused by shear (not flexural). Alternatively, predicted deflections using MCFT for selected slab specimens (S3, S4, and S5) and beam specimens (B4, B5, and B6) are plotted in Figure 21 and Figure 22 along with the experimentally recorded deflections. With respect to the slab specimens, Figure 21 shows that MCFT underestimated the ultimate loads; however predicted reasonably the ultimate deflections. Theoretically determined deflections were consistently $10 \%$ to $35 \%$ higher than the measured strains in all loading stages. This indicates that the computer models were more flexible than the actual specimens. Similar trend was observed for the beam specimens in Figure 22.

\section{COMPARISON WITH DESIGN CODES AND MCFT}

In this section, the theoretical predictions using the design expressions of: (1) ECCS 203 model for slabs and embedded beams (ECCS-S), (2) ECCS 203 model for beams (ECCS-B), (3) Eurocode 2 EN 1992, (4) BS 8110, (5) ACl 318, (6) CSA Standard (CSA 23.4), (7) MCFT, and (8) a proposed modification are evaluated using the experimental results of the current study. The proposed method uses Equation 1 
for slabs and embedded beams with minimum shear reinforcement and the following equation for slabs and beams with shear reinforcement heavier than the minimum amount.

$$
Q_{u l t}=0.16 \sqrt{\frac{f_{c u}}{\gamma_{c}}} b_{w} d+\frac{A_{s t r} f_{y} d}{\gamma_{s} s}
$$

For this evaluation, all strength reduction factors and material strength reduction factors are set equal to unity. For application of ECCS 203 model for beams, the shear resistance of specimens without stirrups was calculated as per the first term in the right hand side of Equation (4). The categories of test data are divided by whether or not shear reinforcement was provided: Category 1 (specimens without shear reinforcement), Category 2 (specimens with shear reinforcement), and Category 3 (include all specimens). Table 2 provides a summary of the evaluation for Category 1 (4 specimens), Category 2 (10 specimens), and for Category 3 (14 specimens). The table lists the mean value, the coefficient of variation, COV, for the parameter $V_{\text {exp }} / N_{\text {prediction. }}$. The COV is the standard deviation divided by the mean value. The standard deviation is the square root of the square of the differences between the mean value of the parameter and individual parameter values divided by the number of samples. A higher mean means typically that the prediction is conservative. A large COV means that the design relationship needs to be adjusted (calibrated) so that it is very conservative for most design situations in order to keep the risk of failure low. As an example, the table shows that specimens without stirrups (Category 1) had a mean value for $V_{\text {exp }} / V_{\text {prediction }}$ for ECCS-S of 2.61 with a coefficient of variation of 0.11 . For making relative evaluations, a COV of less than 0.15 may be considered excellent, from $0.15-0.20$ very good, from $0.20-0.25$ good, from $0.25-0.30$ reasonable, from $0.30-0.35$ poor, and greater than 0.35 is bad [13].

Assuming Gaussian distribution [14] of the experimental data, it is possible to calculate the probability that the experimental strength may be less than the predicted capacity (Probability of $V_{\text {exp }} / V_{\text {prediction }} \leq 1$ ). For the development of codes of practice, the fractile level refers to the percentage of members that, if designed by the provisions, would be expected to fail if the full factored load were applied to the test structure. The appropriate fractile level is frequently a source of debate [13] with values ranging from as low as $5 \%$ to as high as $30 \%$. The Fractile level is listed in Table 2 for the investigated codes and MCFT method. Again, Table 2 shows that the probability of failure for a specimen at the load predicted by ECCS-S provisions is less than $0.01 \%$ for specimens unreinforced in shear. In the following, observations, made from the examination of the data in Table 2, are presented.

A very important measure of performance is the mean for the categories of test data. For Category 1 Specimens (without shear reinforcement), the mean values of $V_{\text {exp }} / V_{\text {prediction }}$ ranged from 1.66 (BS 8110) to 3.45 (ECCS 203-B) with 5 means in the range between 2.25 and 2.61. It is interesting to note that models that do not incorporate size effect yielded higher means. This is evident by comparing ECCS 203-B mean (3.45) to ECCS 203-S mean (2.61) and ACI 318 mean (2.60) to CSA 23.4 mean (2.30). The Egyptian Code predictions were considerably lower than the rest of codes resulting in the highest and second highest mean values for ECCS 203B and ECCS 203-S, respectively. The proposed method yields the same mean as ECCS-S for Category 1 as it uses the same expression. For Category 2 (with shear 
reinforcement), except for ECCS 203-S model, the $V_{\text {exp }} / V_{\text {prediction }}$ mean range was generally narrower with values ranging from 1.23 (BS 8110) to 1.75 (ECCS 203-B). However, ECCS 203-S model has a significantly higher mean of 4.46 . The very high mean for ECCS-S model clearly indicates that its predictions are excessively conservative and are not suitable for design. The mean of the proposed model has a value of 1.59. As shown, the means for Category 1 were generally higher than those of Category 2. This is expected as presence of shear reinforcement gives warning before failure, and hence, lower safety margin is warranted in codes for Category 2 specimens. It is worth mentioning that the lowest mean values for both categories were for BS 8110 with values of 1.66 and 1.23 for Categories 1 and 2, respectively.

Inspecting variation in means revealed that, for Category 1 , the COV ranged from 0.07 to 0.11 . $\mathrm{ACl} 318$ and MCFT had the lowest variation with COV value of 0.07 . This suggests that both methods provide the most uniform factor of safety against failure. $\mathrm{ACl} 318$ and MCFT are based on different theories resulting in different mean values of 2.60 and 2.25 for $V_{\text {exp }} / V_{\text {prediction, }}$ respectively. The rest of models had slightly higher COVs with values ranging between 0.09 and 0.11 . Considering the comparison criteria set earlier, all investigated code methods had excellent COV. However, if one of the eight design methods were to be selected based purely on performance, then either the $\mathrm{ACl}$ or MCFT method would be selected. On the other hand, the COVs for all codes are considerably higher for members with shear reinforcement than for members without shear reinforcement with COVs ranging between 0.12 (excellent-BS 8110) to 0.31 (poor-Eurocode 2 EN 1992). COVs of ACl 318, CSA 23.04, and MCFT are particularly very good and those of ECCS-S and ECCS-B are principally good. The proposed model COV is classified as very good. Considering the mean values along the COVs in both categories, the shear strength prediction of the ACl 318 and CSA 23.4 provide the most accurate and consistent prediction of capacity. The MCFT approach gives very similar results with good levels of accuracy for both categories. The method also provides a unified tool of shear design, which considers all sectional forces in a consistent manner.

On the entity level, the means of ECCS 203-S were 2.61 and 4.46 with excellent and good COVs for Category 1 and 2, respectively. With respect to ECCS 203-B, the means were 3.45 and 1.75 with excellent and good COVs for Category 1 , and 2, respectively. The higher mean for ECCS 203-B compared to that of ECCS 203-S for Category 1 is due to not considering the size and width effect in ECCS 203-B formulation. Eurocode had reasonably excellent performance for Category 1, however for Category 2, COV is uniformly poor with a value of 0.31 . The performance of the $\mathrm{ACl}$ provisions for the two categories were 0.07 and 0.19 , a result considered excellent to very good. The overall performances of CSA simplified provisions are very similar, which is not surprising considering that they both $\mathrm{ACl}$ and CSA have similar formulation. It should be noted that results did not provide a uniform COV for specimens with and without shear reinforcement for ECCS 203-S, ECCS 203-B, Eurocode, ACI 318, and CSA 23.4. The shear capacity predictions in these codes are for shear causing significant diagonal cracking rather than on ultimate shear strength. This is only true in the case of beams or slabs without transverse shear reinforcement and therefore cannot be accurate for elements with transverse reinforcement. The proposed method performed well for both shear unreinforced and shear reinforced specimens. 
It is interesting to note that the fractile levels of Category 1 Specimens were less than $0.01 \%$ for all investigated methods. On the other hand, it ranged between $0.1 \%$ (ECCS 203-S) to 23\% (EUROCODE 1992) for Category 2 Specimens. It was expected that ECCS 203-S would have the lowest fractile level as it totally ignore the shear reinforcement contribution in the shear resistance of the elements. On the other hand, ECCS 203-B, BS 8110, ACl 318, CSA 23.4, MCFT, and proposed method provide reasonable fractile level of less than $10 \%$.

\section{CONCLUSIONS}

The following conclusions were drawn from the results of the experimental program on the 14 slab and beam specimens and the accompanied theoretical work:

(1) The effectiveness of shear reinforcement in the form of vertical stirrups is very evident in both slab and beam specimens. The beam and slab specimens with stirrups were able to resist higher shear stresses than those without shear reinforcement.

(2) Increasing the amount of longitudinal steel reinforcement increases the shear strength. The influence of the longitudinal steel ratio is more pronounced in slabs and embedded beams as its role in controlling crack widths is higher than in the deeper elements.

(3) Increasing the amount of shear reinforcement increases the shear stress at failure in both slab and beam specimens. Beam specimens failed by high compression in the webs when high percentages of shear reinforcement $(>1.5 \%)$ were used.

(4) Using anchored stirrups in both the tension and compression zones is essential for slab specimens to fully develop the ultimate shear capacity as evident by the behaviour of Slabs S2, S3, and S4.

(5) The ECCS 203-07 expression for the prediction of the shear strength of slabs and embedded beams is highly conservative. This expression should be revised to include a term to account for the presence of shear reinforcement. In this respect, the expression that computes the shear reinforcement contribution to the shear strength of regular beams with shear reinforcement can be added to the current expression. Further, the expression should be generalized to account for the effect of the longitudinal steel ratio.

(6) The Eurocode shear prediction formula performed poor for specimens with shear reinforcement. The method had the least margin of safety for specimens with shear reinforcement.

(7) BS 8110 assigned safety margin for specimens without shear reinforcement is lower than all other investigated codes and methods.

(8) The ACl and CSA 23.4 expressions for the prediction of the shear strength are conservative in their predictions for all of the tested elements with very good performance for specimens with shear reinforcement.

(9) The modified compression field theory accounts for important parameters such as the shear interaction with moment, the main reinforcement ratio and the aggregate size. Further, the method gives good prediction for the ultimate shear strength of specimens with and without shear reinforcement. It provides a higher safety margin for specimens without shear reinforcement.

(10) Response 2000 is a computer-based program that utilizes MCFT. It gives a good agreement with experimental test results. This software provides an easy and 
practical tool for accurate calculations of the shear strength of reinforced concrete elements with all sectional forces considered.

\section{REFERENCES}

[1] Permanent Committee for the Code of Practice for Design and Construction of Reinforced Concrete Structures, "Egyptian Code of Practice for Design and Construction of Concrete Structures (ECCS 203-2007)", Housing and Building Research Center, Giza, 2007.

[2] Commission of the European Communities, Eurocode No. 2: Design of Concrete Structures-Part 1: General Rules and Rules for Buildings. EN 1992-1-1, 2004.

[3] British Standard Institution, BS 8110: Part 1, Structural Use of Concrete: Part 1, Code of Practice for Design and Construction, BSI, London, 1997.

[4] ACl Committee 318, Building Code Requirements for Reinforced Concrete (ACl318-05), American Concrete Institute, Detroit, USA, 2008.

[5] CSA Committee A23.3, Design of Concrete Structures, CSA-A23.3-2004. Rexdale, Ontario, Canada, 2004.

[6] Collins, M.P, Mitchell, D., Adebar, P. E., and F.J. Vecchio, "A General Shear Design Method" ACI Structural Journal, Vol. 93, No. 1, pp. 36-45, ACl, 1996.

[7] Vecchio, F.J., and M.P. Collins, "Predicting the Response of Reinforced Concrete Beams Subjected to Shear Using the Modified Compression Field Theory", ACl Structural Journal, Vol. 85, No.3, pp. 258-268, 1988.

[8] Bentz, E. C., and M. P. Collins, "Response 2000", a computer aided software based on the MCFT, http://www.ecf.utoronto.ca/ bentz/r2k.htm, 2008.

[9] Collins, M.P., E.C. Bentz, "Response 2000: Reinforced Concrete Sectional Analysis using the Modified Compression Field Theory", Version 1.0.5, University of Toronto, Canada, 2000.

[10] G.N. Kani, "Basic Facts Concerning Shear Failure ", ACl Journal, Vol. 63, No. 6, pp. 675-692, 1966.

[11] A.H. Khalil, "Influence of Coarse Aggregate and Stirrup Spacing on the Shear Capacity of RC Beams", Proceedings of the Tenth International Colloquium on Structural and Geotechnical Engineering, Paper E03RC42, 16 pages, Ain Shams University, Cairo, Egypt, April 2003.

[12] ASCE-ACl Committee on Shear and Torsion, "Recent Approaches to Shear Design of Structural Concrete", Journal of Structural Engineering, Vol. 124, No. 12, ASCE, 1998.

[13] Neil M. Hawkins, Daniel A. Kuchma, Robert F. Mast, M. Lee Marsh, and KarlHeinz Reineck, Simplified Shear Design of Structural Concrete Members, NCHRP, report 549, National Cooperative Highway Research Program, Transportation Research Board, Washington, USA, 2005.

[14] Evans, M., Hastings, N., and Brian Peacock, Statistical Distribution, John Wiley and Sons, New York, USA, 2000. 
Table 1. Details of the test specimens along with cracking and failure loads

\begin{tabular}{|c|c|c|c|c|c|c|c|c|c|}
\hline & & $\begin{array}{l}\mathrm{f}_{\mathrm{cu}} \\
\mathrm{MPa}\end{array}$ & $\begin{array}{l}\text { Bottom } \\
\text { rft }\end{array}$ & Top rft & $\begin{array}{c}\text { Stirrups, } \\
\rho_{v}\end{array}$ & $\begin{array}{l}\mathrm{P}_{\mathrm{fc}}{ }^{\mathrm{a}} \\
(\mathrm{kN})\end{array}$ & $\begin{array}{l}\mathrm{P}_{\mathrm{sc}}^{\mathrm{b}} \\
(\mathrm{kN})\end{array}$ & $\begin{array}{l}\mathrm{Pult}^{\mathrm{c}} \\
(\mathrm{kN})\end{array}$ & $\begin{array}{l}\text { Failure } \\
\text { mode }^{d}\end{array}$ \\
\hline \multirow[t]{5}{*}{ Group } & & 25 & $\begin{array}{c}\text { Y16+ } \\
\text { Y12/rib }\end{array}$ & - & - & 70 & 130 & 140 & $\bar{T}$ \\
\hline & S2 & 25 & $2 Y 18 /$ rib & - & $\begin{array}{l}\mathrm{R} 8-200 \\
0.5 \%\end{array}$ & 80 & 140 & 180 & $\mathrm{~T}$ \\
\hline & S3 & 25 & 2Y18/rib & - & $\begin{array}{l}\mathrm{R} 8-200 \\
0.5 \%\end{array}$ & 80 & 160 & 220 & $\mathrm{~T}$ \\
\hline & S4 & 25 & 2Y22/rib & 2Y10/rib & $\begin{array}{l}\text { R8-100 } \\
0.5 \%\end{array}$ & 90 & 150 & 210 & T \\
\hline & S5 & 25 & 4Y22/rib & 2Y22/rib & $\begin{array}{l}\mathrm{R} 8-100 \\
1 \%\end{array}$ & 120 & 170 & 260 & C \\
\hline \multirow{6}{*}{ Group } & B1 & 25 & $3 Y 16$ & $2 Y 10$ & - & 70 & 120 & 155 & $\mathrm{~T}$ \\
\hline & B2 & 25 & 4Y22 & 2Y16 & - & 70 & 120 & 180 & $\mathrm{~T}$ \\
\hline & B3 & 25 & 4Y22 & $2 Y 16$ & $\begin{array}{l}\mathrm{R} 8-200 \\
0.25 \%\end{array}$ & 80 & 130 & 200 & $\mathrm{~T}$ \\
\hline & B4 & 25 & 4Y22 & 2Y16 & $\begin{array}{l}\text { R8-100, } \\
0.5 \%\end{array}$ & 80 & 140 & 280 & $\mathrm{~T}$ \\
\hline & B5 & 25 & 6Y22 & 2Y22 & $\begin{array}{l}\text { Y10-100, } \\
0.8 \%\end{array}$ & 100 & 160 & 340 & $\mathrm{~T}$ \\
\hline & B6 & 25 & 8Y22 & 4Y22 & $\begin{array}{l}\text { Y10-50, } \\
1.6 \%\end{array}$ & 160 & 200 & 400 & C \\
\hline \multirow{3}{*}{$\begin{array}{l}\text { Group } \\
\text { III }\end{array}$} & $\mathrm{R}$ & 27 & $5 Y 18$ & - & - & 90 & 170 & 255 & $\mathrm{~T}$ \\
\hline & W1 & 27 & 7Y18 & 4Y10 & $\begin{array}{l}\mathrm{R} 8-200 \\
0.25 \%\end{array}$ & 120 & 210 & 380 & $\mathrm{~T}$ \\
\hline & W2 & 27 & 8Y22 & 4Y18 & $\begin{array}{l}\text { R8-85, } \\
0.6 \%\end{array}$ & 140 & 280 & 550 & $\mathrm{~T}$ \\
\hline \multicolumn{10}{|c|}{$\begin{array}{l}{ }^{\mathrm{a}} \text { flexural cracking load }{ }^{\mathrm{b}} \text { shear cracking loads }{ }^{\mathrm{c}} \text { failure load } \\
{ }^{\mathrm{d}} \mathrm{T}=\text { Shear tension failure and } \mathrm{C}=\text { extensive cracking of the web and bearing failure at support }\end{array}$} \\
\hline \multicolumn{5}{|c|}{ Members (number) } & $\begin{array}{l}\text { Without } \\
\text { stirrups (4) }\end{array}$ & \multicolumn{2}{|c|}{$\begin{array}{l}\text { With stirrups } \\
(10)\end{array}$} & \multicolumn{2}{|c|}{$\begin{array}{l}\text { Both } \\
(14)\end{array}$} \\
\hline \multirow{2}{*}{\multicolumn{3}{|c|}{$\begin{array}{l}\text { ECCS 203-slab anc } \\
\text { embedded beams } \\
\text { ECCS 203-beams }\end{array}$}} & \multicolumn{2}{|c|}{$\begin{array}{c}\text { Mean (COV) } \\
\text { Fractile }\end{array}$} & $\begin{array}{l}2.61(0.11) \\
<0.01 \%\end{array}$ & \multicolumn{2}{|c|}{$\begin{array}{c}4.46(0.24) \\
0.1 \%\end{array}$} & \multicolumn{2}{|c|}{$\begin{array}{c}3.93(0.32) \\
1.1 \%\end{array}$} \\
\hline & & & \multicolumn{2}{|c|}{$\begin{array}{l}\text { Mean (COV) } \\
\text { Fractile }\end{array}$} & $\begin{array}{l}3.45(0.11) \\
<0.01 \%\end{array}$ & \multicolumn{2}{|c|}{$1.75(0.21)$} & \multicolumn{2}{|c|}{$\begin{array}{c}2.23(0.39) \\
7.9 \%\end{array}$} \\
\hline \multicolumn{3}{|c|}{ Eurocode-1992 } & \multicolumn{2}{|c|}{$\begin{array}{l}\text { Mean (COV) } \\
\text { Fractile }\end{array}$} & $\begin{array}{l}2.61(0.10) \\
<0.01 \%\end{array}$ & \multicolumn{2}{|c|}{$1.30(0.31)$} & \multicolumn{2}{|c|}{$\begin{array}{c}1.67(0.43) \\
17.6 \%\end{array}$} \\
\hline \multicolumn{3}{|c|}{ BS 8110} & \multicolumn{2}{|c|}{$\begin{array}{l}\text { Mean (COV) } \\
\text { Fractile }\end{array}$} & $\begin{array}{c}1.66(0.09) \\
<0.01 \%\end{array}$ & \multicolumn{2}{|c|}{$\begin{array}{c}1.23(0.12) \\
6.0 \%\end{array}$} & \multicolumn{2}{|c|}{$\begin{array}{c}1.36(0.18) \\
7.1 \%\end{array}$} \\
\hline \multicolumn{3}{|c|}{$\mathrm{ACl} 318-08$} & \multicolumn{2}{|c|}{$\begin{array}{l}\text { Mean (COV) } \\
\text { Fractile }\end{array}$} & $\begin{array}{c}2.60(0.07) \\
<0.01 \%\end{array}$ & \multicolumn{2}{|c|}{$\begin{array}{c}1.53(0.19) \\
3.4 \%\end{array}$} & \multicolumn{2}{|c|}{$\begin{array}{c}1.83(0.31) \\
7.2 \%\end{array}$} \\
\hline \multicolumn{3}{|c|}{ CSA 23.4-04 } & \multicolumn{2}{|c|}{$\begin{array}{l}\text { Mean (COV) } \\
\text { Fractile }\end{array}$} & $\begin{array}{l}2.31(0.11) \\
<0.01 \%\end{array}$ & $\begin{array}{c}1.49(0.1 \varepsilon \\
3.4 \%\end{array}$ & & $\begin{array}{r}1.72( \\
6.1\end{array}$ & $\begin{array}{l}0.27) \\
\%\end{array}$ \\
\hline \multicolumn{3}{|c|}{ MCFT } & \multicolumn{2}{|c|}{$\begin{array}{l}\text { Mean (COV) } \\
\text { Fractile }\end{array}$} & $\begin{array}{l}2.25(0.07) \\
<0.01 \%\end{array}$ & $\begin{array}{c}1.27(0.1 \\
9.3 \%\end{array}$ & & $\begin{array}{r}1.55 \\
13.5\end{array}$ & $\begin{array}{l}0.32) \\
\%\end{array}$ \\
\hline Propo & sed $m$ & ethod & $\begin{array}{r}\text { Mean } \\
\text { Fra }\end{array}$ & $\begin{array}{l}\text { (COV) } \\
\text { tile }\end{array}$ & $\begin{array}{l}2.61(0.11) \\
<0.01 \%\end{array}$ & $\begin{array}{c}1.59(0.1) \\
1.5 \%\end{array}$ & & $\begin{array}{r}1.88( \\
5.4\end{array}$ & $\begin{array}{l}.29) \\
\%\end{array}$ \\
\hline
\end{tabular}




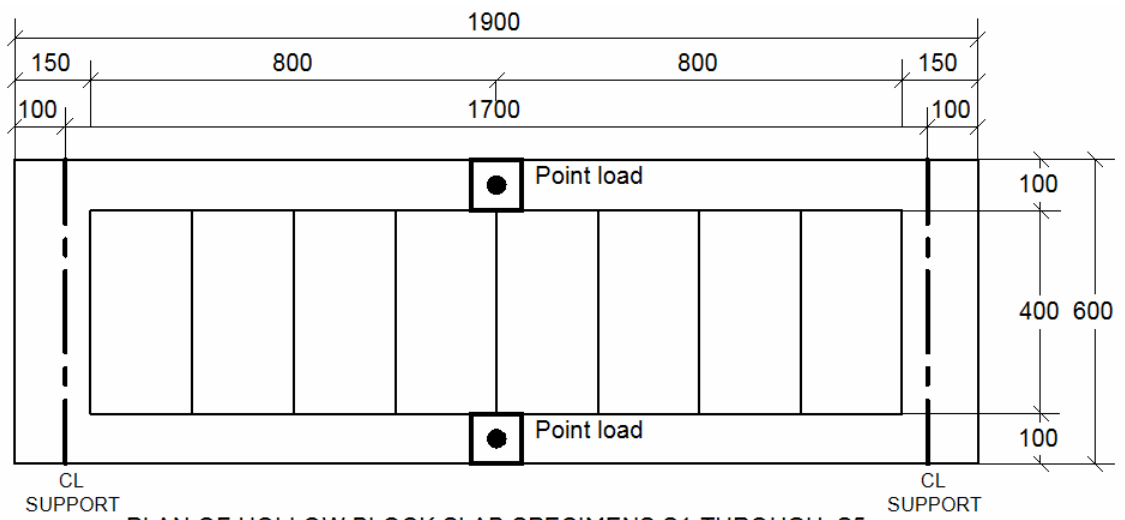

PLAN OF HOLLOW BLOCK SLAB SPECIMENS S1 THROUGH S5

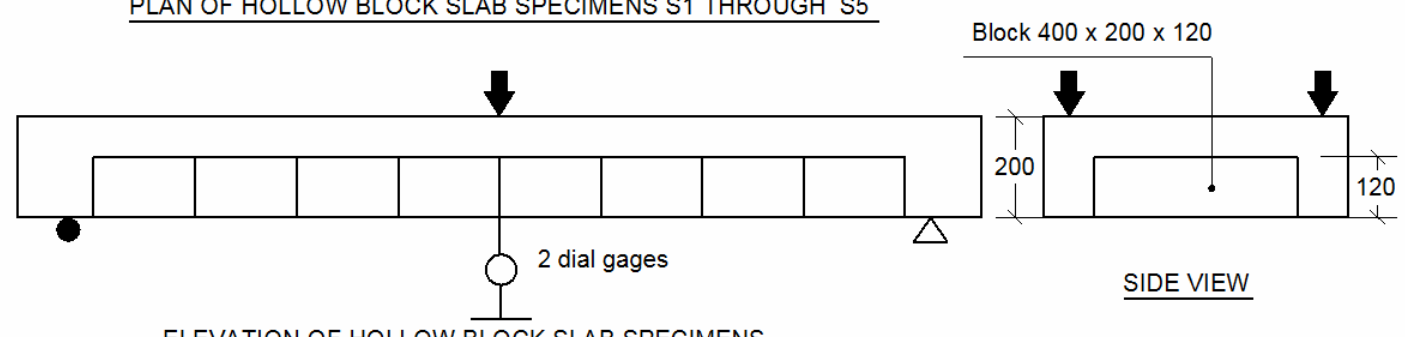

ELEVATION OF HOLLOW BLOCK SLAB SPECIMENS

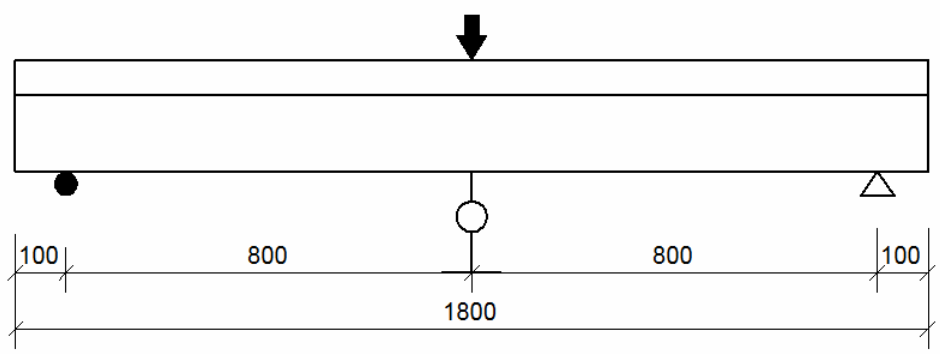

ELEVATION OF BEAM SPECIMENS B1 THROUGH B6

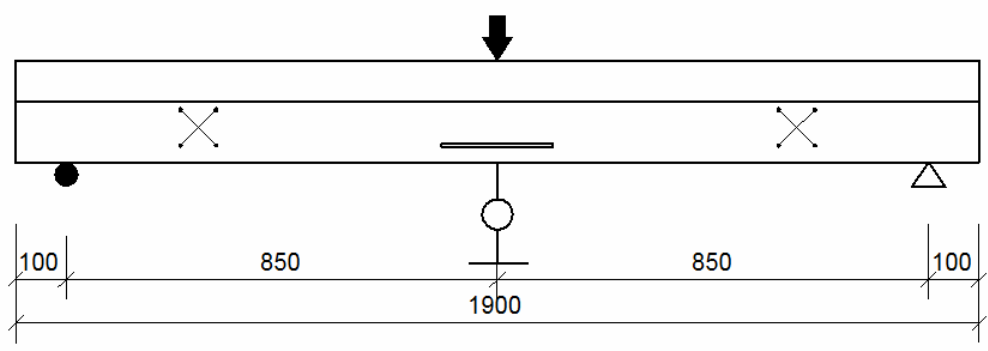

ELEVATION OF BEAM RW, W1, AND W2

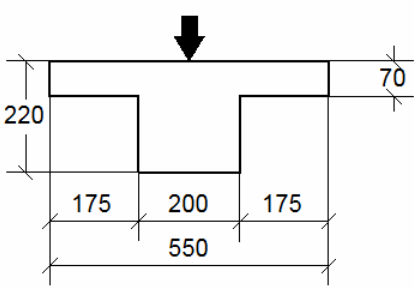

SIDE VIEW
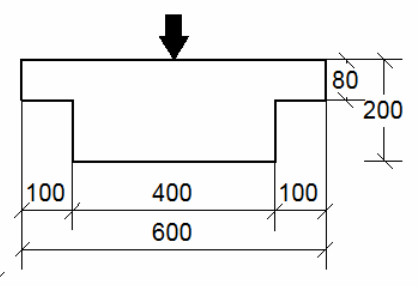

SIDE VIEW

Figure 1. Concrete dimensions of the test specimens

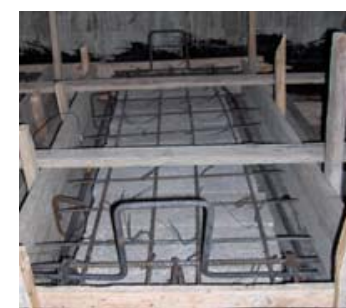

S1

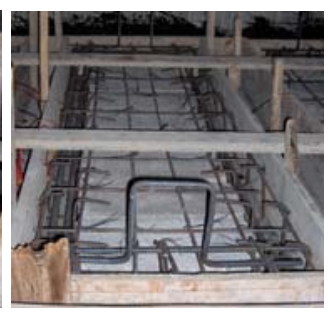

S2

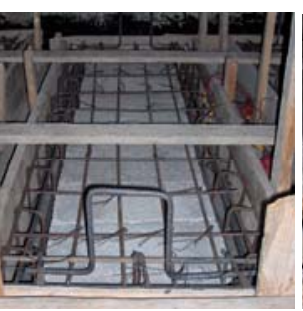

S3

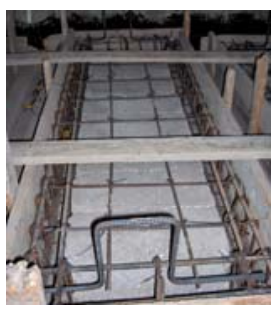

S4

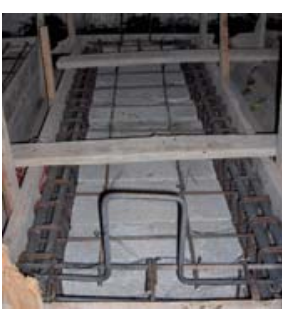

S5

Figure 2. Reinforcement in forms ready for casting for Specimens S1 through S5 


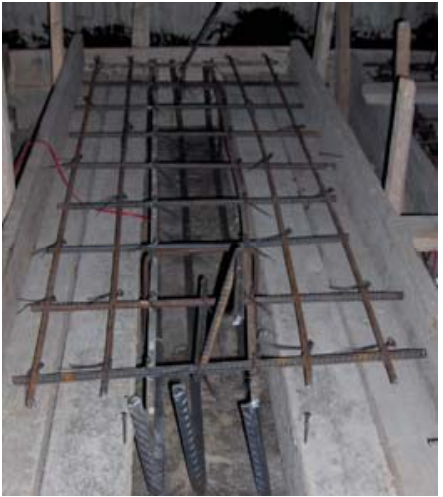

B1

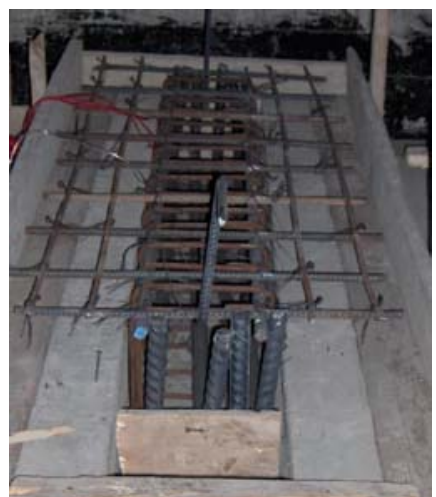

B4

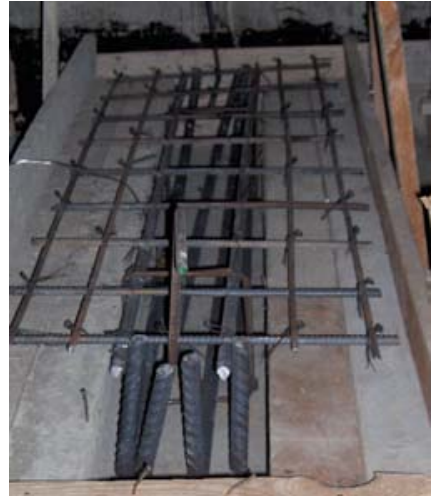

B2

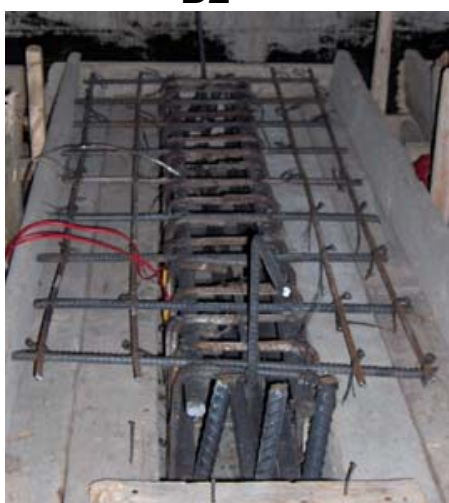

B5

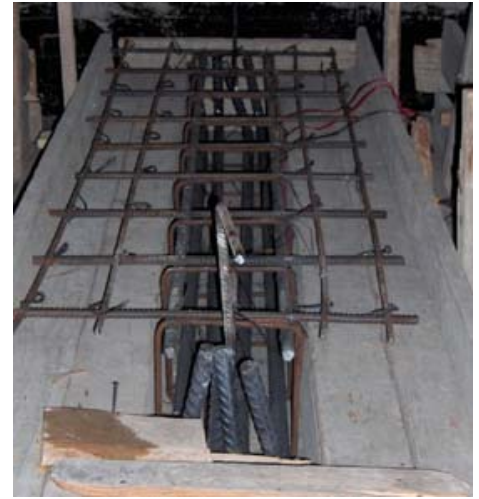

B3

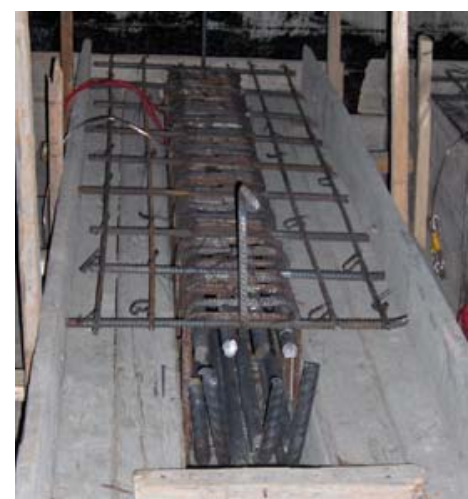

B6

Figure 3. Reinforcement in forms ready for casting for Specimens B1 through B6
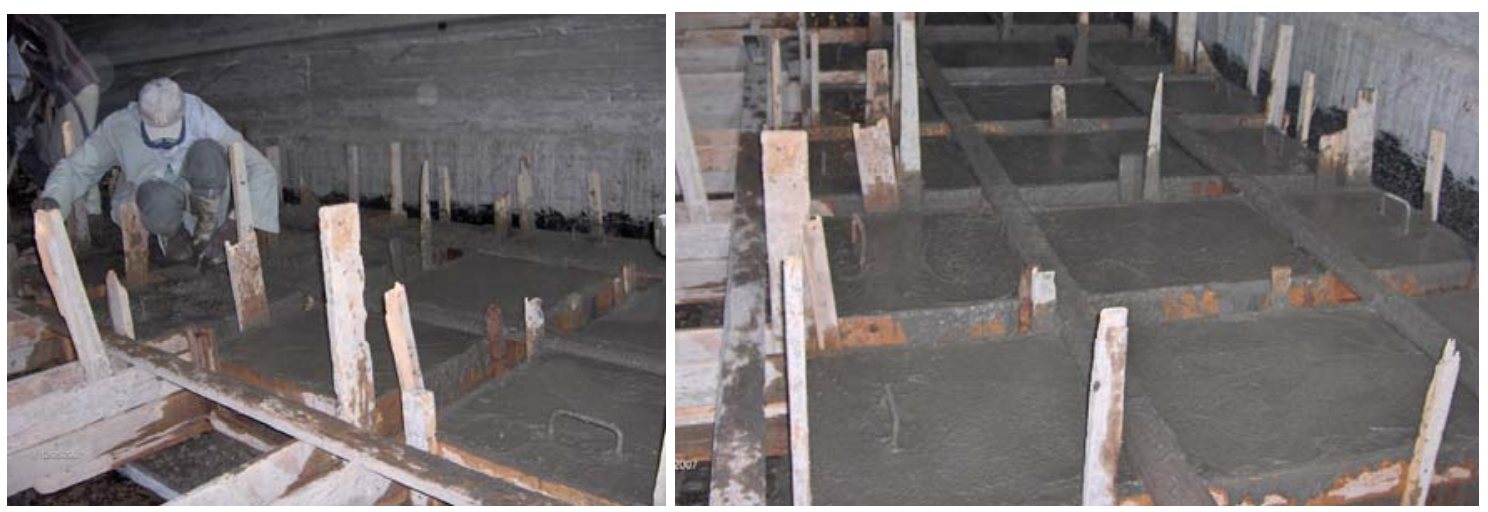

Figure 4. Casting the Specimens

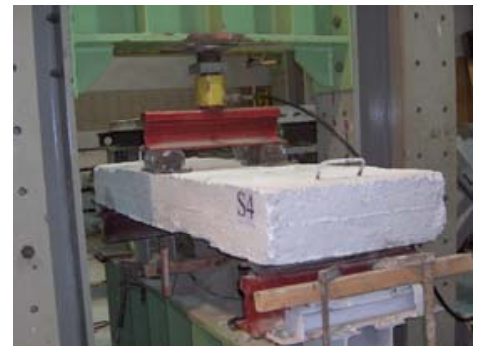

Group I

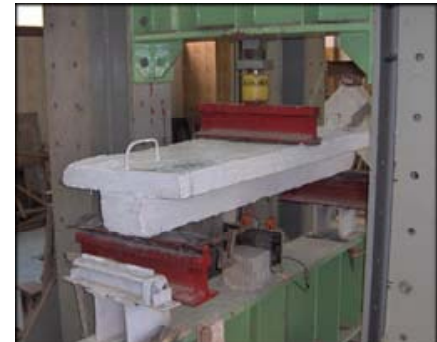

Group II

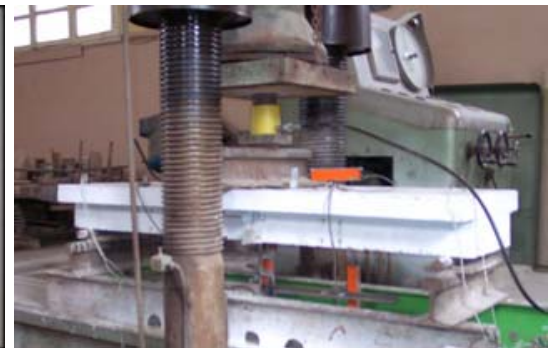

Group III

Figure 5. Test setup and instrumentation 


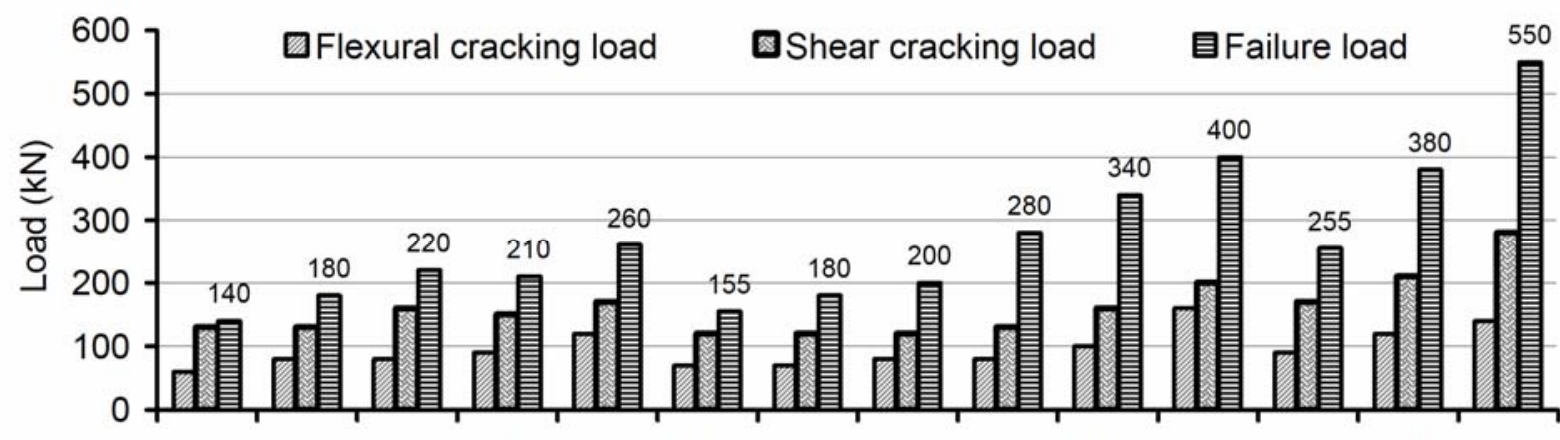

$\begin{array}{llllllllllllll}\text { S1 } & \text { S2 } & \text { S3 } & \text { S4 } & \text { S5 } & \text { B1 } & \text { B2 } & \text { B3 } & \text { B4 } & \text { B5 } & \text { B6 } & \text { R } & \text { W1 } & \text { W2 }\end{array}$

Figure 6 . Cracking and failure loads of the test specimens
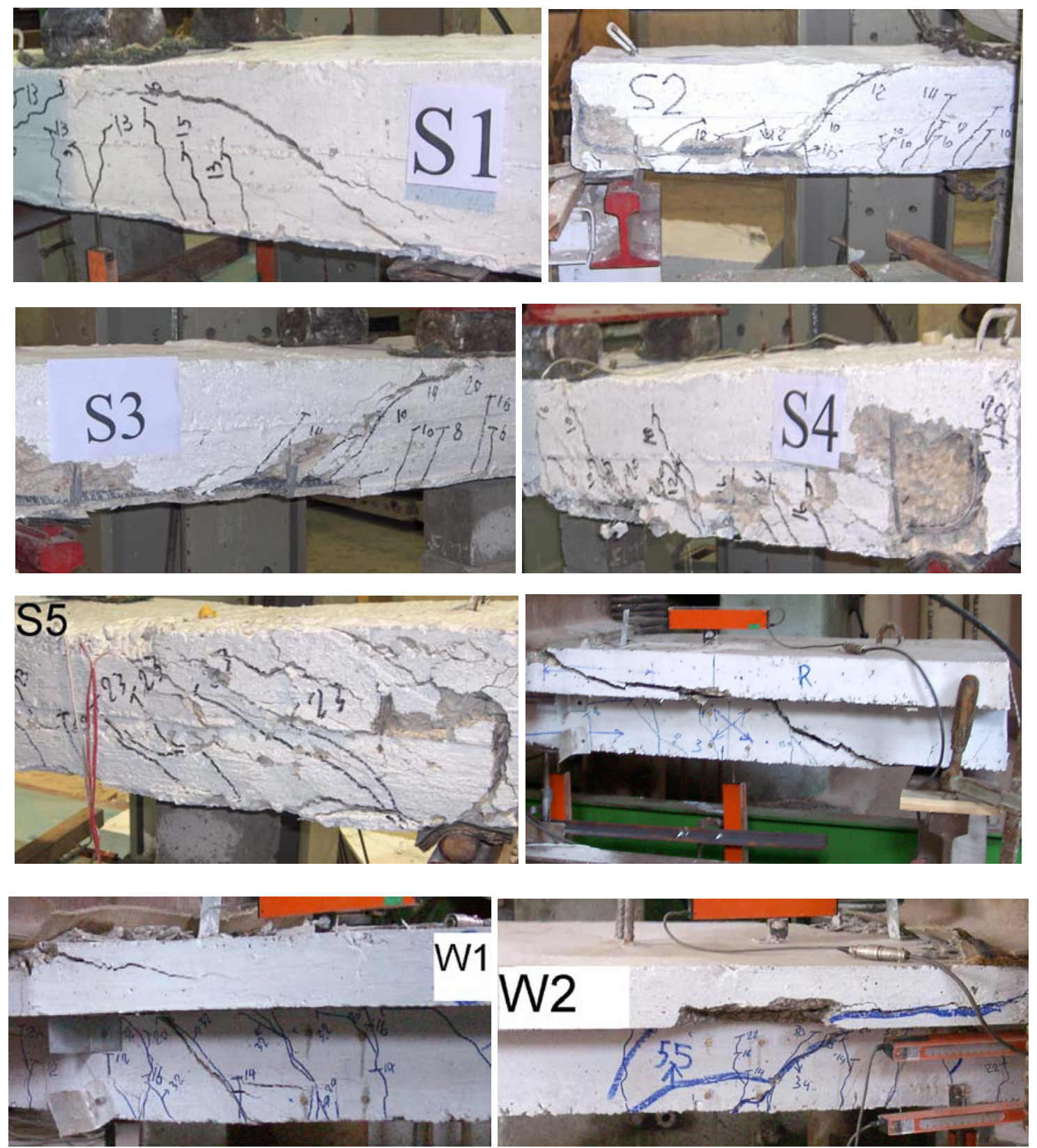

Figure 7. Typical failure patterns of Groups I and III 

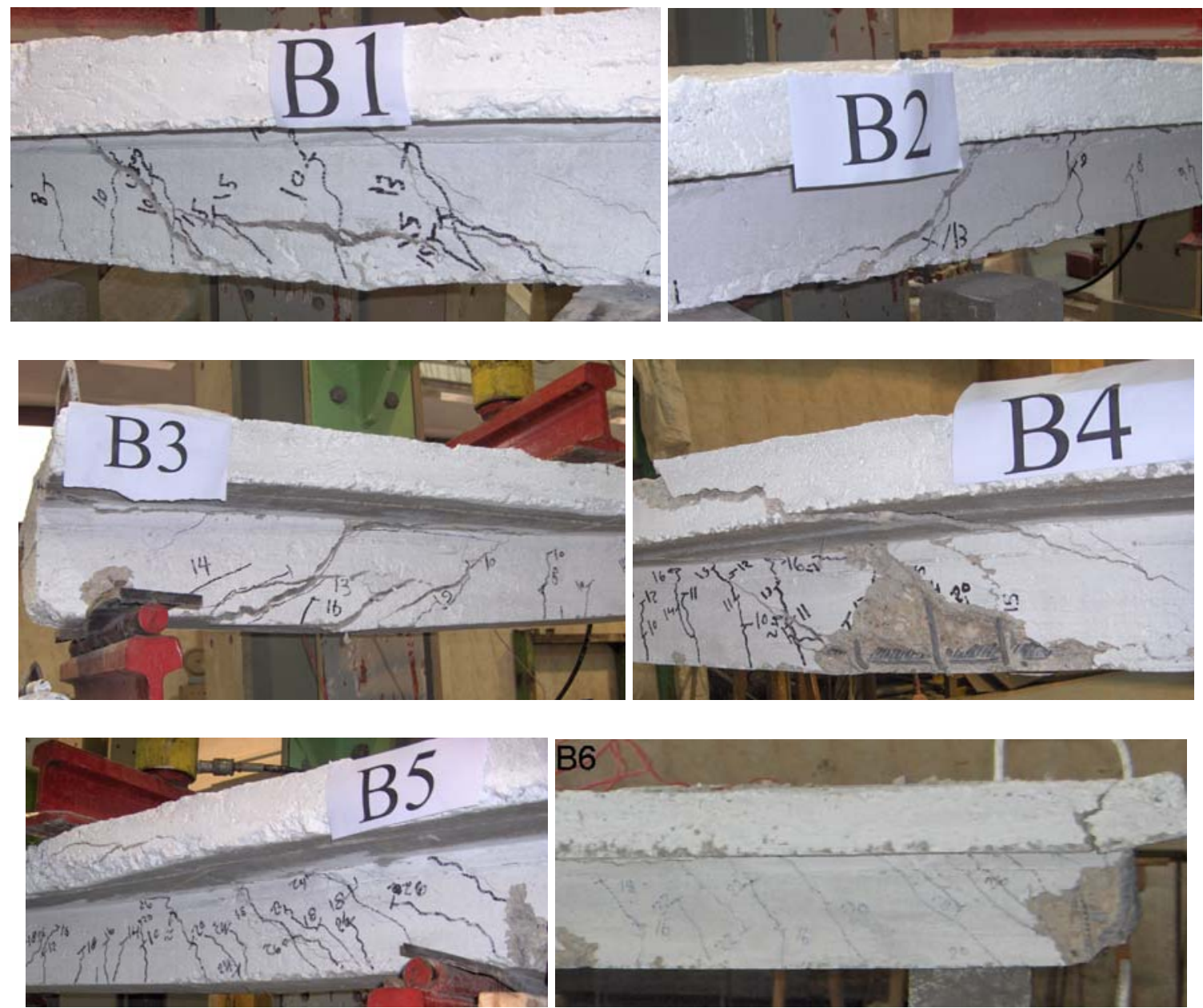

Figure 8. Typical failure patterns of Group II

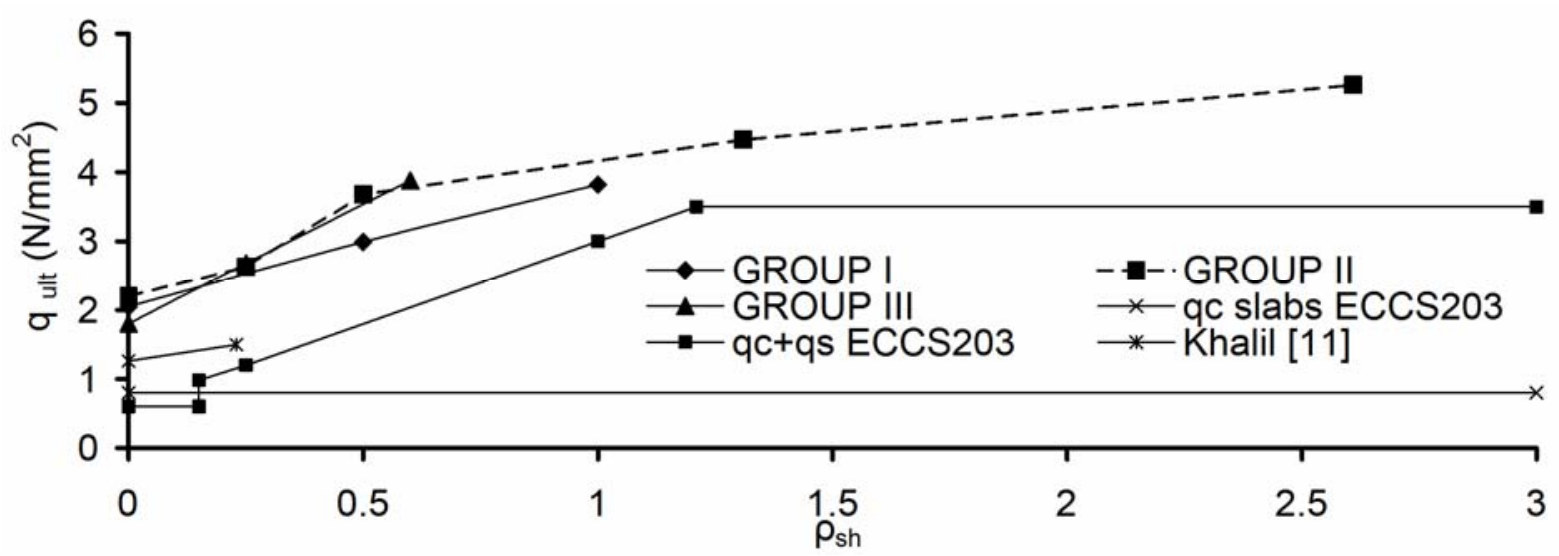

Figure 9. Relation between stirrup reinforcement ratio and the ultimate shear stress 


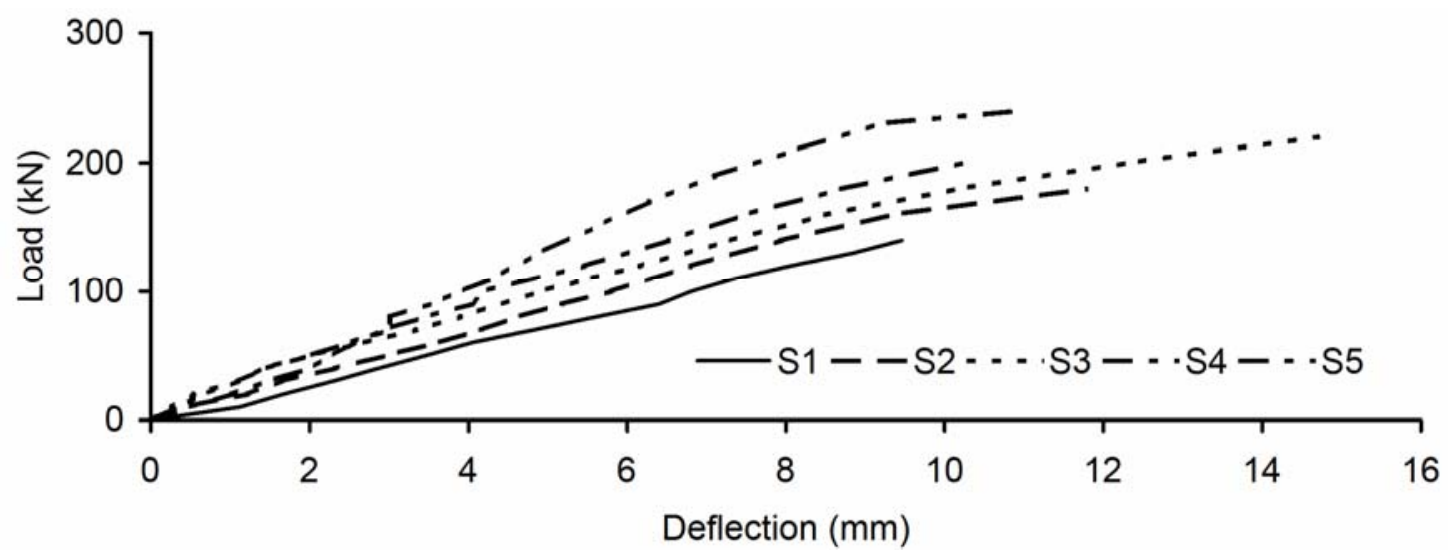

Figure 10. Load-mid span deflection for Group I specimens

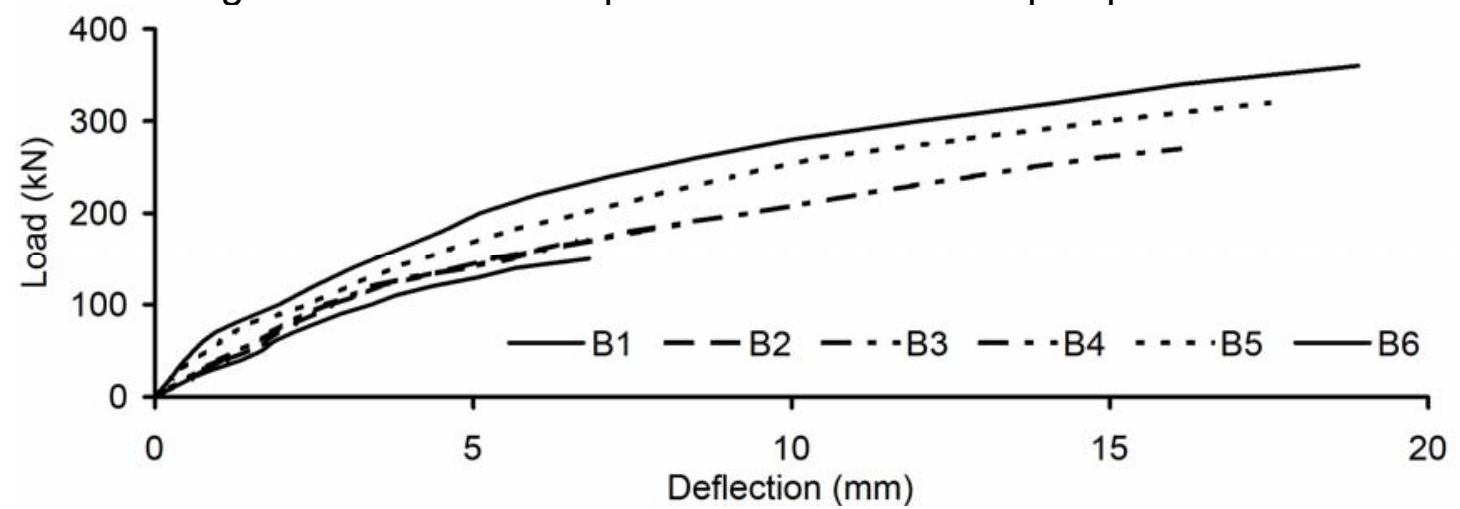

Figure 11. Load-mid span deflection for Group II specimens

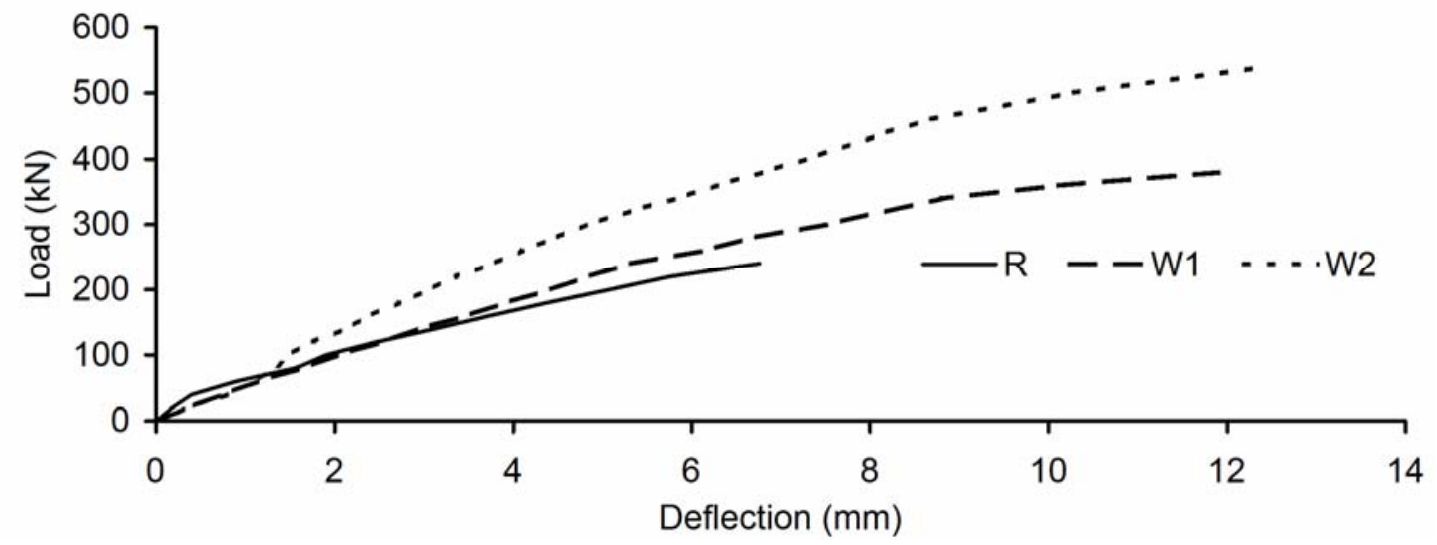

Figure 12. Load-mid span deflection for Group III specimens

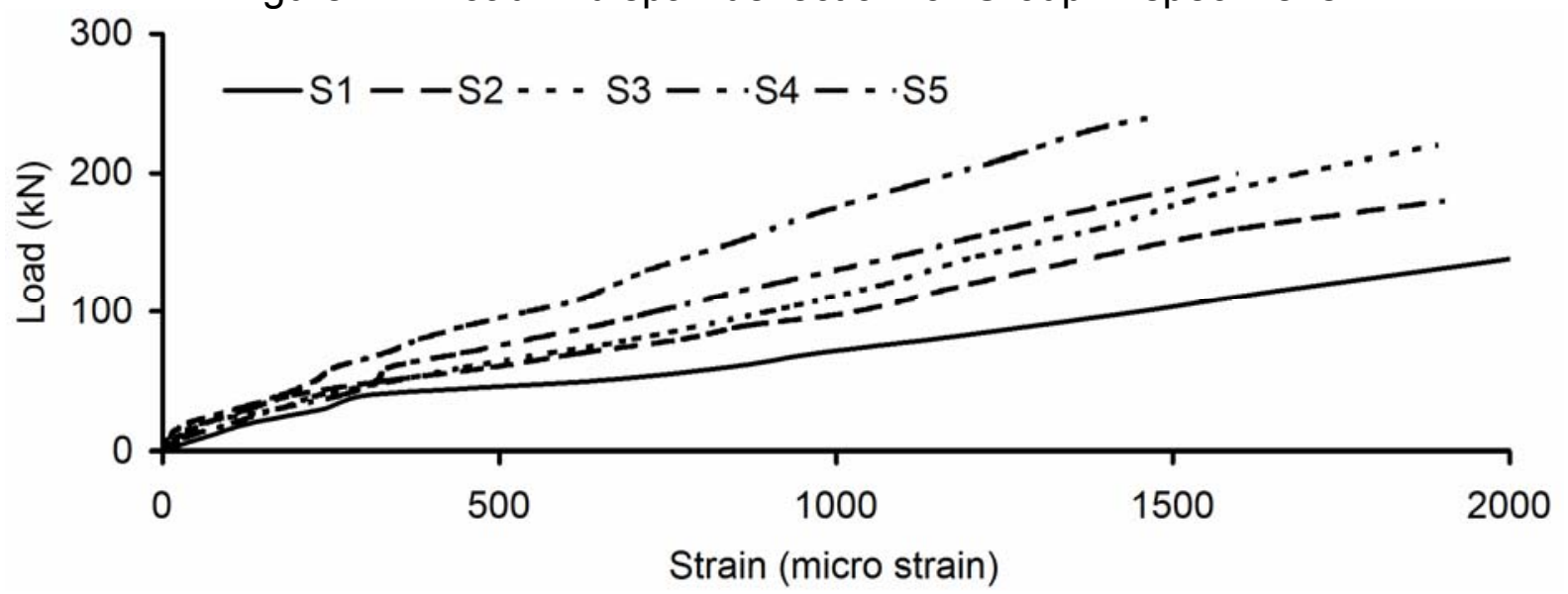

Figure 13. Load-longitudinal reinforcement strains for Group I 


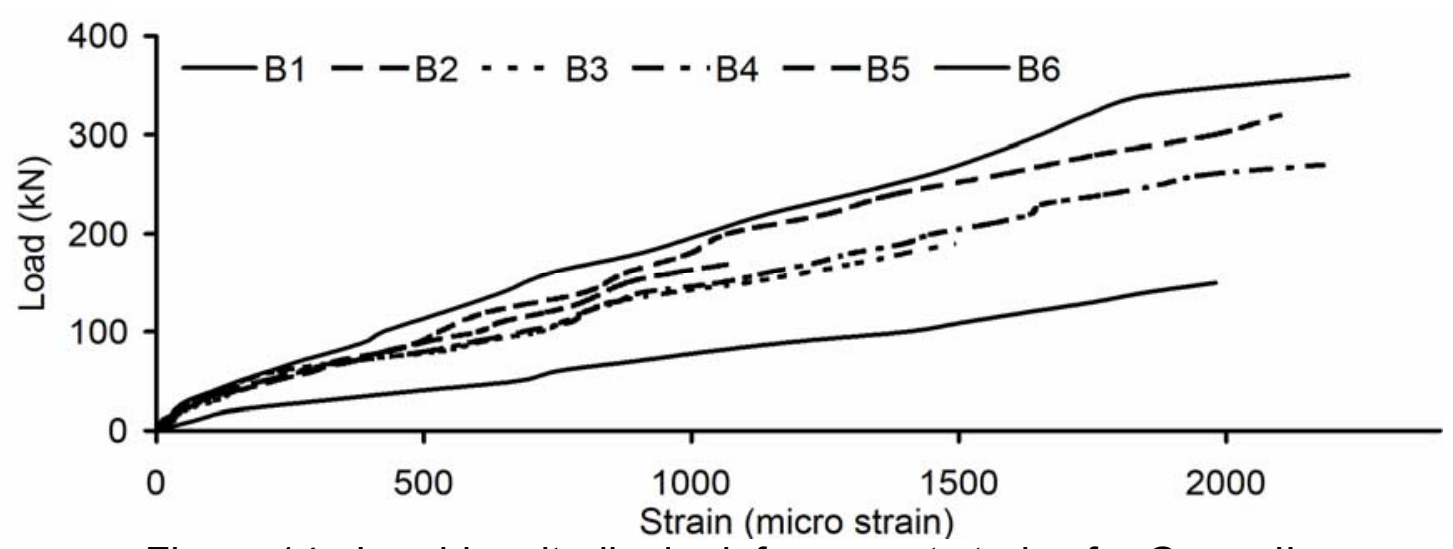

Figure 14. Load-longitudinal reinforcement strains for Group II

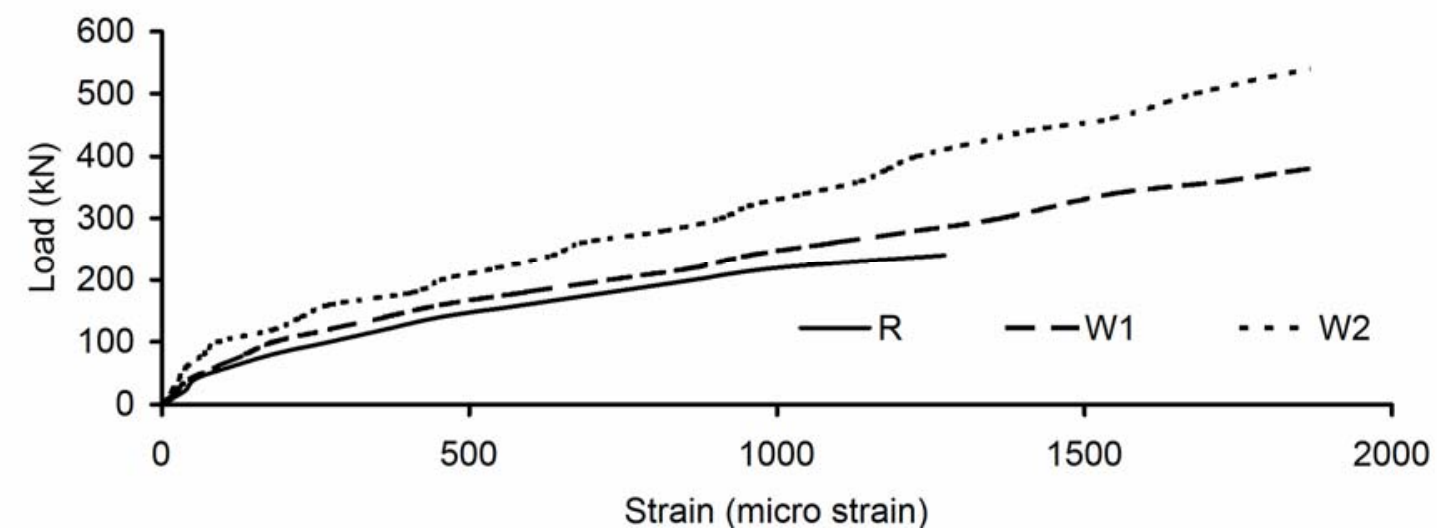

Figure 15. Load-longitudinal reinforcement strains for Group III

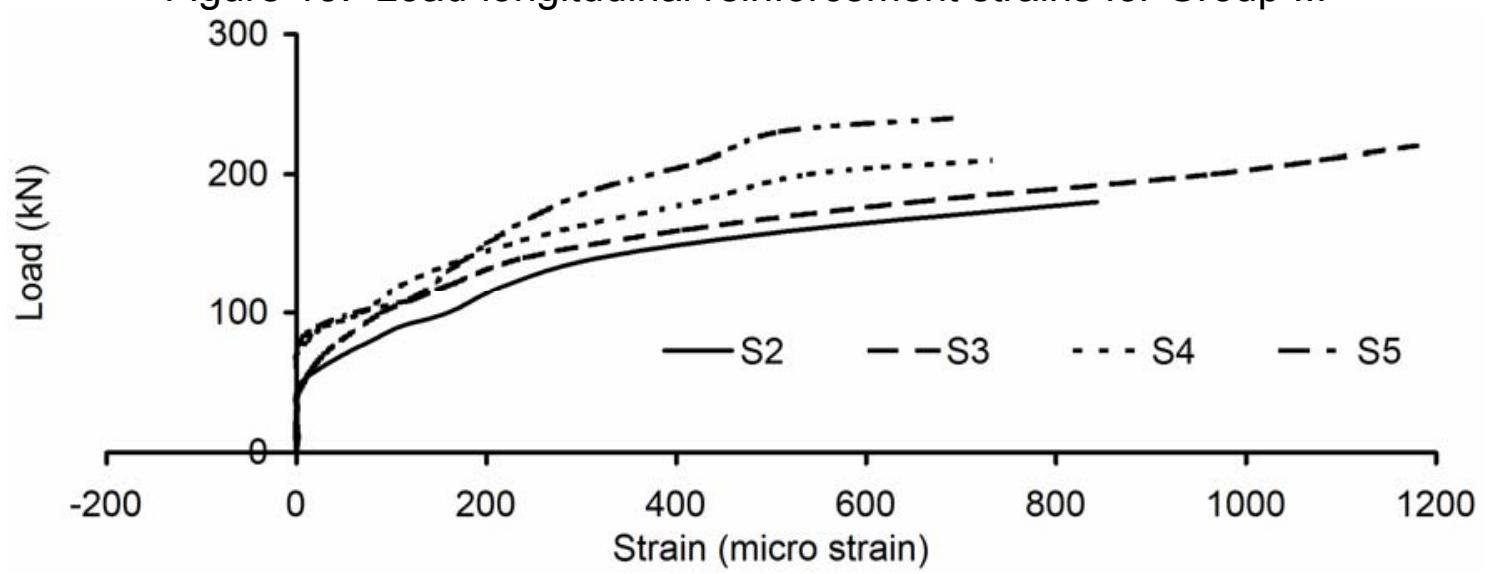

Figure 16. Load-maximum stirrup strains for Group I

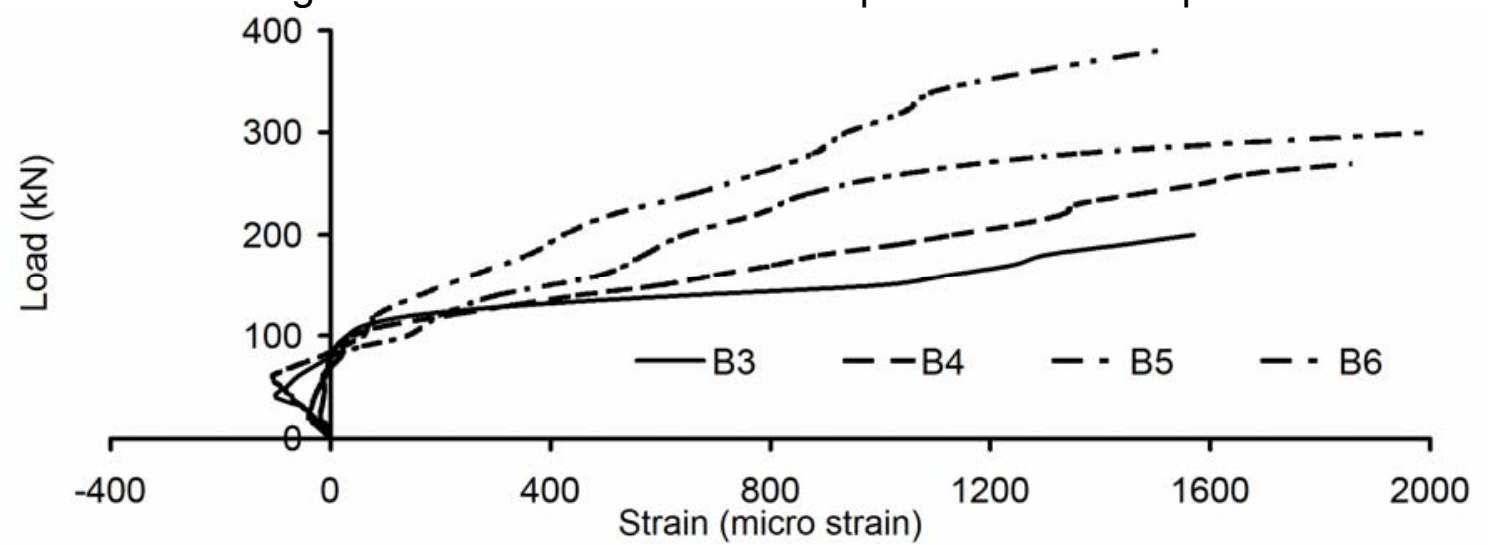

Figure 17. Load-maximum stirrup strains for Group II 


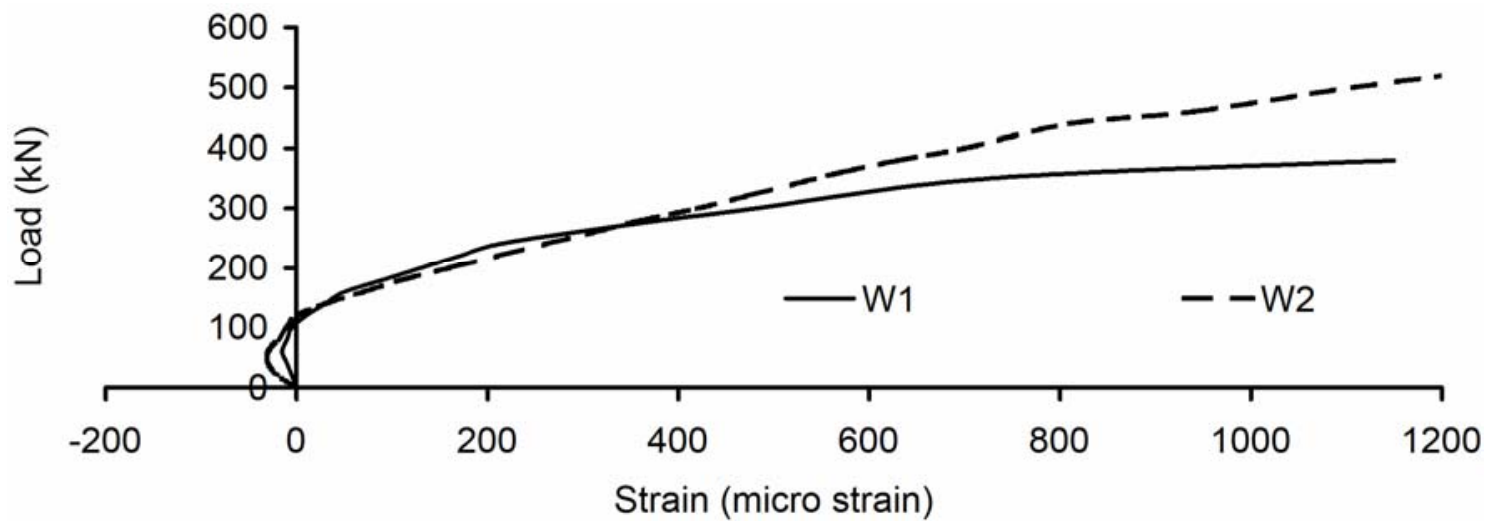

Figure 18. Load-maximum stirrup strains for Group III

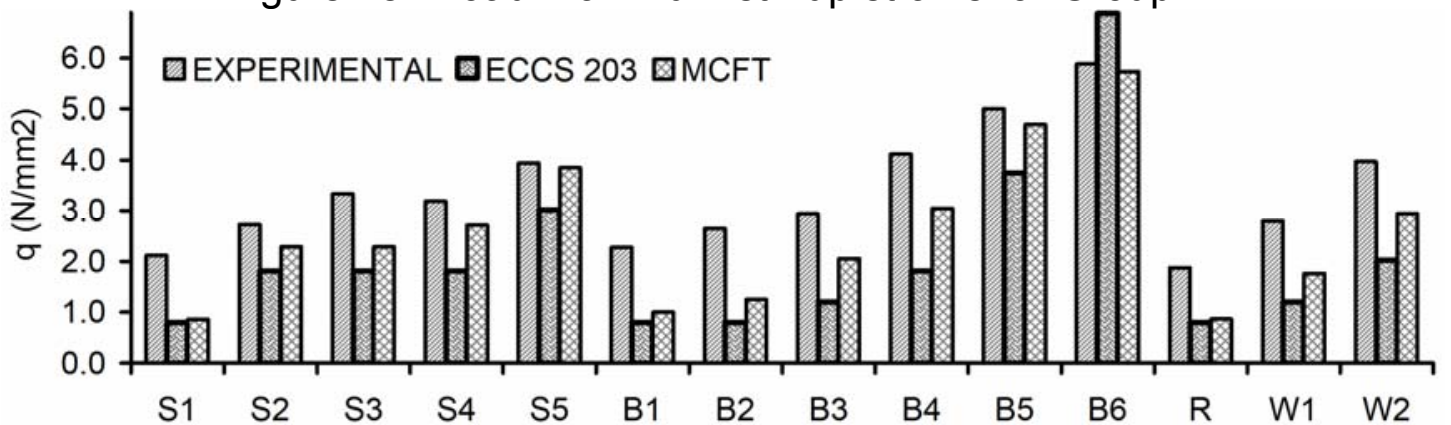

Figure 19. Comparison among shear strengths

(experimental results, ECCS 203 prediction, and MCFT prediction)
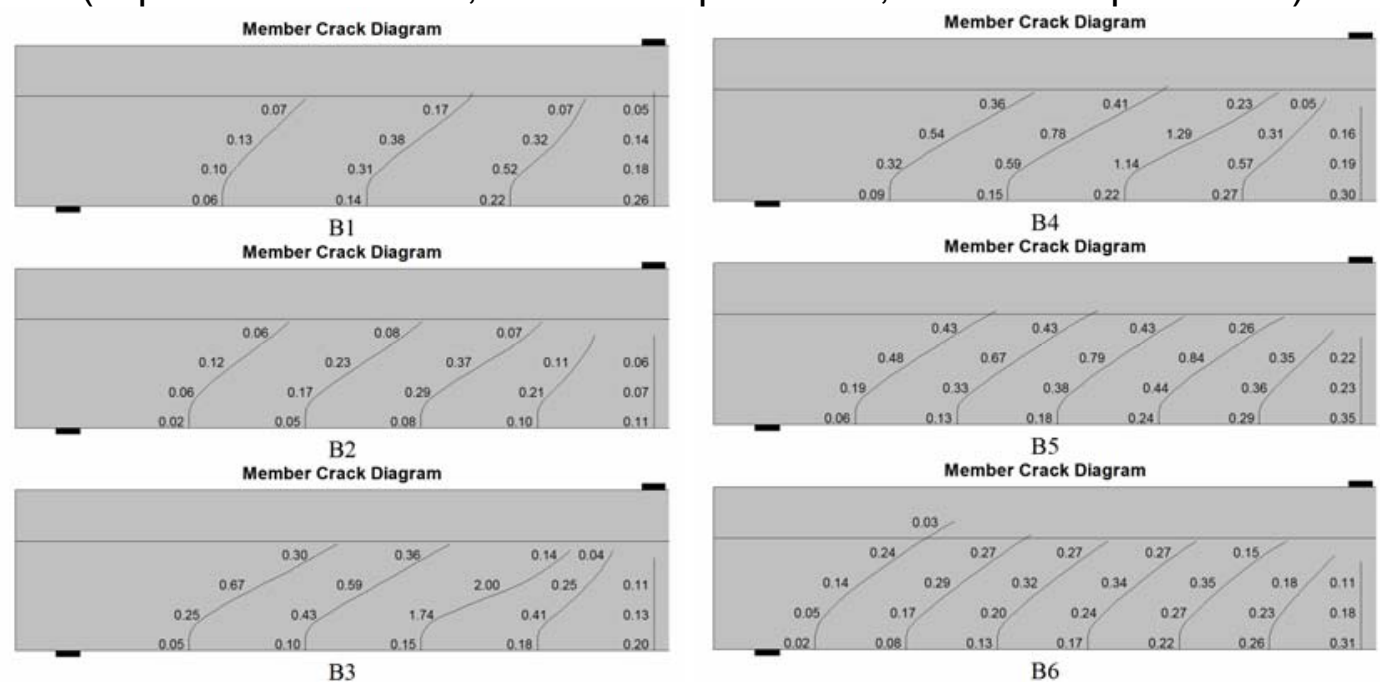

Figure 20. Crack pattern and distribution predicted by MCFT

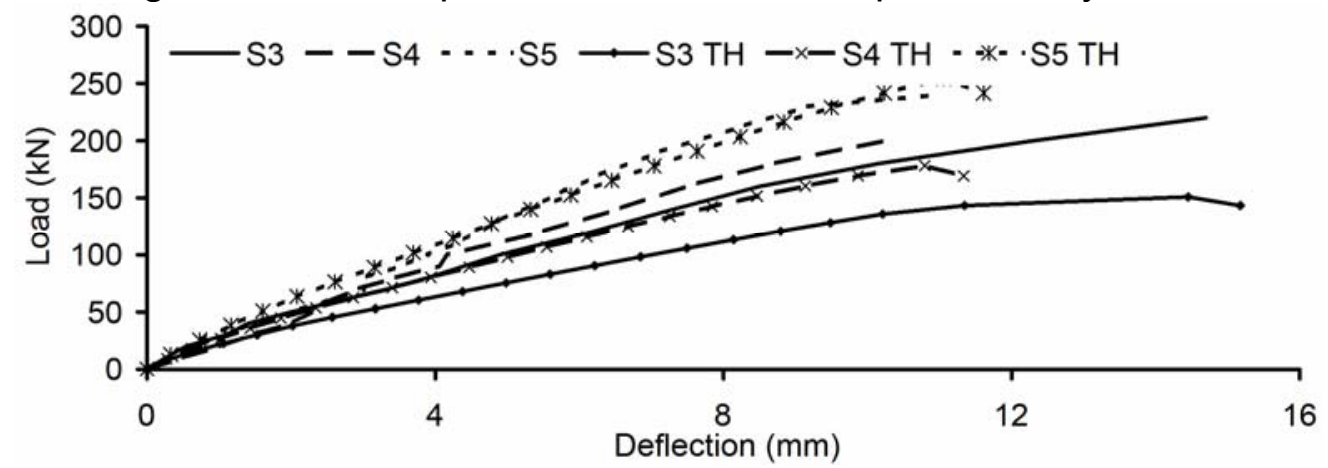

Figure 21. Comparison between theoretical and experimental deflections (Group I) 


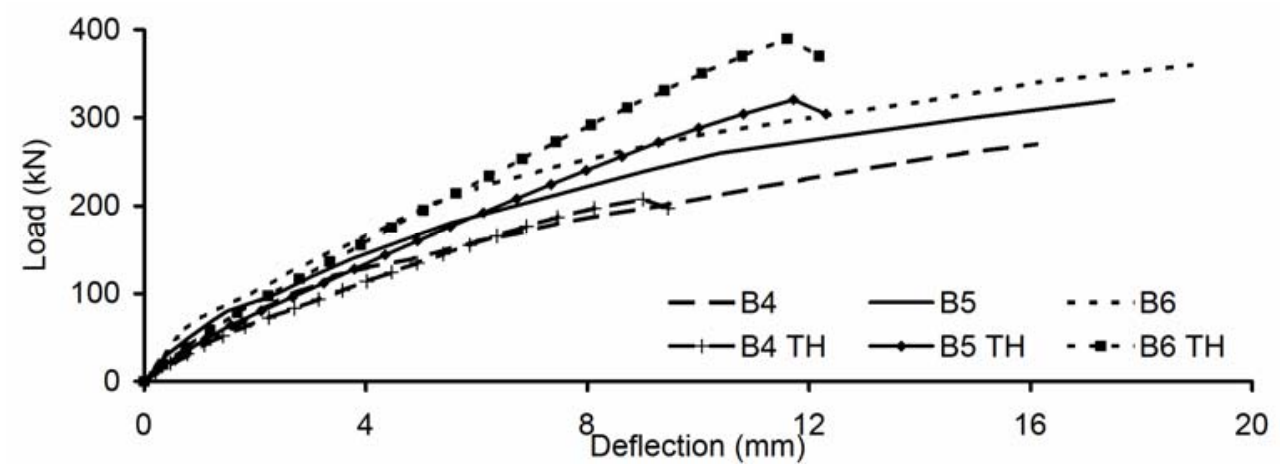

Figure 22. Comparison between theoretical and experimental deflections (Group II) 